\title{
L'eau et le feu : chronique des études pallava
}

\section{Emmanuel Francis, Valérie Gillet, Charlotte Schmid}

\section{Citer ce document / Cite this document :}

Francis Emmanuel, Gillet Valérie, Schmid Charlotte. L'eau et le feu : chronique des études pallava. In: Bulletin de l'Ecole française d'Extrême-Orient. Tome 92, 2005. pp. 581-611;

doi : https://doi.org/10.3406/befeo.2005.6002

https://www.persee.fr/doc/befeo_0336-1519_2005_num_92_1_6002

Fichier pdf généré le 08/11/2019 


\title{
Rapports et missions
}

\section{L'eau et le feu : chronique des études pallava}

\author{
Emmanuel Francis (doctorant, Louvain, boursier FSR), Valérie GILLET \\ (docteure, Paris III, boursière EFEO) et Charlotte SCHMID (maître de \\ conférences, EFEO) ${ }^{1}$
}

Les études pallava sont, en quelque sorte, une tradition de l'EFEO. Victor Goloubew (1914 et 1921) est, avec Gabriel Jouveau-Dubreuil, le premier à lire la monumentale composition du grand rocher à Mahābalipuram comme la descente du Gange. Tous deux s'opposaient ainsi à l'interprétation, prévalant jusqu'alors, de l'épisode du Kirātārjunīya, pour des raisons qui nous paraissent toujours valables aujourd'hui : on ne peut comprendre les Pallava sans donner sa juste place au symbolisme de l'eau. Jacques Dumarçay et Françoise L'Hernault (1975) ont poursuivi l'étude de cette dynastie dans les "Mémoires Archéologiques " de l'EFEO avec la publication de monographies sur quatre temples pallava construits (le Temple du Rivage, le temple de Panaimalai, le Piravāttānēévara à Kāñcīpuram, le Vīrațān̄eśvara à Tiruttaṇi). Nos propres réflexions sur les images de Dakșināmūrti et de Lingodbhavamūrti mettent en lumière l'importance du feu dans l'iconographie pallava. Ces deux éléments - eau et feu - rythmeront en quelque sorte cette chronique.

Hasard ou nécessité ? - nos chemins se sont croisés en 2000 dans le centre de l'EFEO de Pondichéry. Deux d'entre nous s'engageaient alors dans une thèse de doctorat centrée sur les Pallava - Valérie Gillet sur la sculpture narrative et Emmanuel Francis sur l'idéologie royale - tandis que Charlotte Schmid, après avoir étudié l'iconographie ancienne de Viṣnu-Krṣṇa dans l'Inde du Nord, commençait à s'intéresser aux premières images brahmaniques méridionales. Notre désir de collaboration s'est alors concrétisé dans le travail de terrain et dans un projet de recherche commun sur les Pallava, inscrit au dernier quadriennal de l'EFEO, et auquel s'est joint Sylvain Brocquet, auteur d'une thèse sur le kāvya épigraphique de cette dynastie (S. Brocquet 1997). Dans les pages qui suivent nous présentons les premiers résultats de nos recherches, personnelles et conjointes, tout en signalant les dernières découvertes archéologiques et épigraphiques, ainsi que quelques publications récentes.

1. C'est un grand plaisir de remercier ici pour leur disponibilité et leur enthousiasme, au centre de l'EFEO à Pondichéry, T. S. Gangadharan, Dominic Goodall, T. V. Gopal Iyer $(\dagger)$, N. Ramaswamy, G. Ravindran, Varada Desikan, G. Vijayavenugopal et Eva Wilden, et, à l'Archaeological Survey of India, S. Rajavelu et $\mathrm{S}$. Swaminathan. Un grand merci également à Leslie Orr qui a relu cette chronique. 


\section{Enrichissement des sources}

Le tsunami qui a ravagé l'Asie en décembre 2004 n'a pas épargné Mahābalipuram mais y a révélé des restes archéologiques, de même qu'à Cāluvarkuppam, quelques kilomètres plus au nord, non loin de la "Grotte du Tigre ». Les recherches menées par l'Archaeological Survey of India sont en cours et la presse tant indienne qu'internationale s'en est fait l'écho ${ }^{2}$. Il nous semble cependant prématuré de se prononcer sur le caractère royal de ces découvertes : d'après les informations diffusées, les structures mises au jour ne correspondent pas aux types architecturaux royaux et nulle inscription royale de fondation en sanskrit n'a été trouvée. Il n'en reste pas moins qu'il s'agit vraisemblablement de vestiges de l'époque des Pallava, c'està-dire d'une découverte très importante puisque la documentation ne s'est guère enrichie depuis les publications de A. H. Longhurst (1924-1930), hormis le chantier archéologique ouvert au nord du Temple du Rivage au début des années 1990, évoqué ci-dessous.

Par ailleurs, lors de notre travail de terrain sur le site en février 2004, nous avons reconstitué ${ }^{3}$, à partir de débris abandonnés au sud du complexe, un édicule circulaire composé de quatre fragments (fig. la-c). Sur ses faces extérieures, des lions dressés séparent trois panneaux où nous identifions Kālārimūrti, Nrọttamūrti et Dakṣināmūrti, qui fait là l'une de ses premières apparitions connues ${ }^{4}$.

Le corpus d'inscriptions s'est étoffé depuis le travail de T. V. Mahalingam paru en 1988, mais dont le manuscrit avait été déposé en 1976. Quelques inscriptions royales ont été publiées. Les tablettes de Nandivarman III de Kumaradimañgalam (N. Ramesan 1976) offrent un nouvel exemple de sa praśasti, tandis que les tablettes d'A parājitavarman trouvées à Vēlañcēri (R. Nagaswamy 1979) ont clarifié sa position généalogique dans la dynastie en l'identifiant comme le fils de Kampavarman, lui-même rival de Nrpatungavarman. Quant aux tablettes de Kumāraviṣnuvarman découvertes à Babbēpalli (P. V. Parabrahma Sastry 1992), elles confirment l'historicité de son père Karālavarman et de son grand-père Skandamūlavarman, connus dans l'inscription postérieure, à Vāyalūr, sous les noms de Karāla et de Skandamūla. Enfin, il faut noter au Temple du Rivage, trois nouvelles inscriptions de Narasimhhavarman II : sur le socle du Varāha du bassin, sur le bord supérieur du même bassin, et sur ce qui est vraisemblablement un chapiteau de colonne, gisant au sud du complexe

2. Les informations parues dans la presse indienne (articles de The Hindu [2005: 28/01, 10/04, 29/04, 12/07, $21 / 09 ; 2006: 28 / 03$ ] et Frontline [vol. 22.10,22.22]) font état des découvertes suivantes. À Mahābalipuram, au sud du Temple du Rivage : la cella d'un temple, un puits avec dispositif en terre cuite, des pierres portant des marques de sculpteurs et une inscription tamoule. À Cāluvarkuppam : un temple de Subrahmanya, dont des piliers portent des inscriptions de la période des Pallava, construit sur ce qui serait le plus ancien temple du Tamil Nadu, constitué de briques dont le format est considéré comme très antique.

3. Nous remercions ici Arlo Griffiths d'avoir mis ses bras musclés à contribution lors de l'opération de remontage.

4. Cet édicule est formé de deux pierres taillées en fer à cheval, brisées toutes deux en deux fragments. La présence de Dakṣināmūrti, que l'on supposera orienté au sud comme tous les Dakṣināmūrti pallava, permet de déterminer une ouverture à l'ouest. La configuration Kālārimūrti au nord, Nrrttamūrti à l'est, Dakṣināmūrti au sud est la même dans la majorité des temples pallava construits, infra: : 591-597. 
Fig. 1. Édicule au Temple du Rivage à Mahābalipuram, vilı siècle. Clichés : E. Francis.
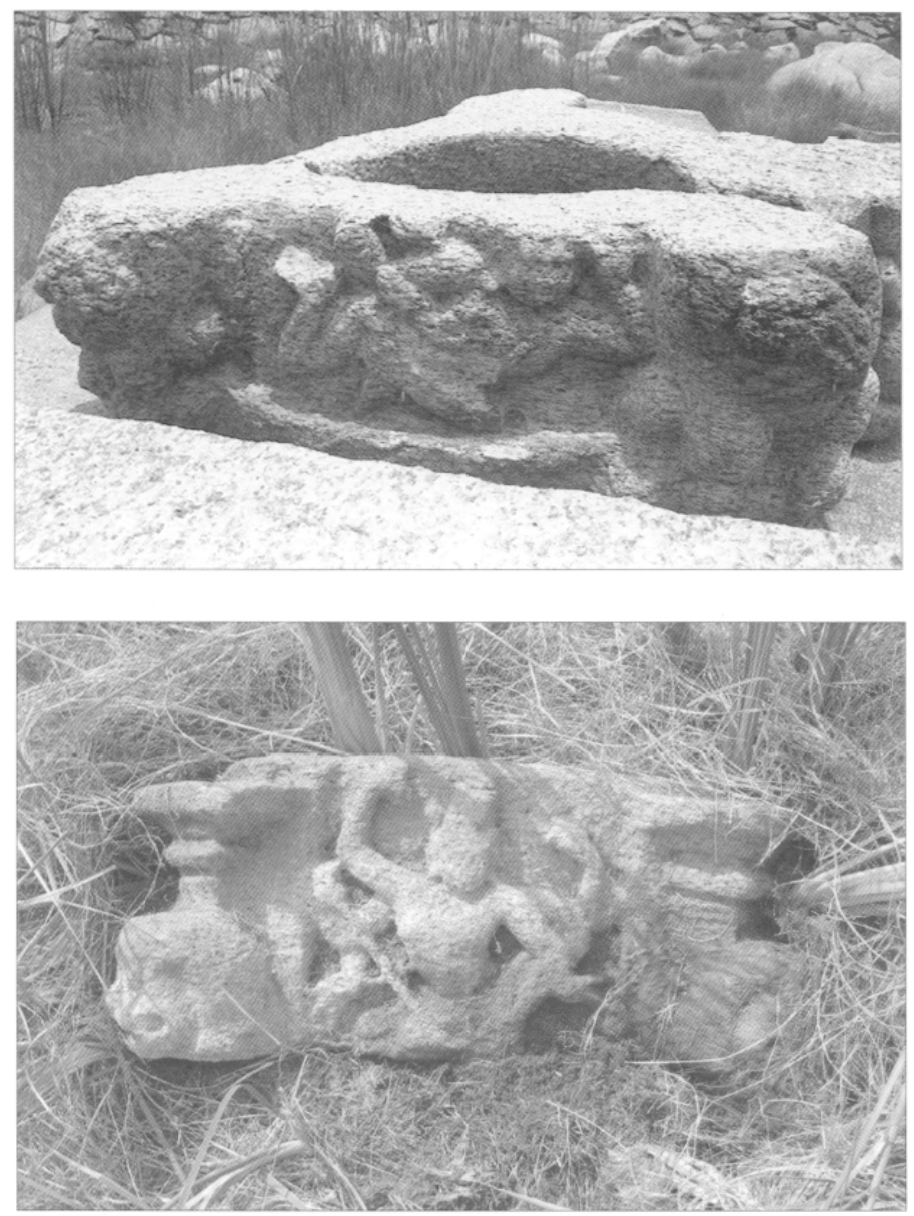

a. Moitié inférieure du Kălārimūrti

b. Moitié supérieure du Kālārimūrti

\section{c. Le Dakṣiṇāmūrti} reconstitué

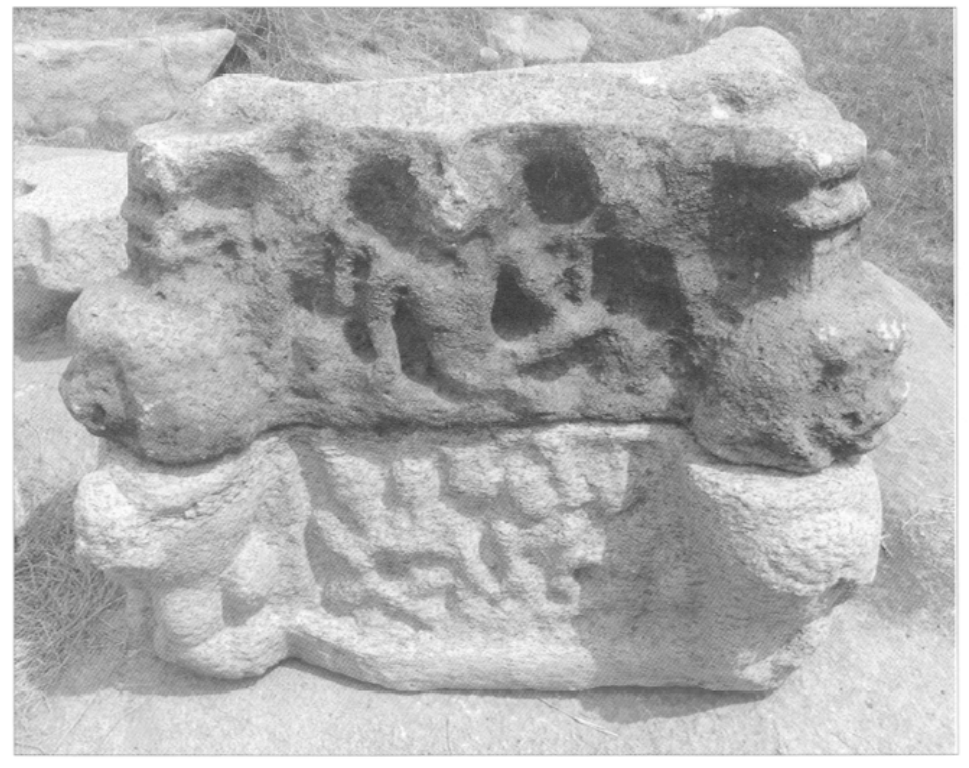


(M. Lockwood 2001 : 223-224, 263-265). Seule cette dernière est originale, le texte des deux autres étant attesté dans d'autres inscriptions ${ }^{5}$. Un nombre plus important d'inscriptions locales datées en année de règne d'un roi Pallava ont été répertoriées dans les différents Annual Reports on Epigraphy [ci-après $A R E]^{6}$.

Nous signalons pour notre part deux nouvelles inscriptions sanskrites au Kailāsanātha, non encore répertoriées à notre connaissance et découvertes au cours de nos missions de terrain. L'une, en caractères grantha, est gravée sur la face sud du Mahendravarmeśvaragrha, et l'autre, en caractères " nāgari ${ }^{7}{ }^{7}$, se trouve sur la base de l'enceinte du Mahendravarmeśvaragrha. En outre, au Temple du Rivage, une inscription sanskrite et grantha (fig. 2) s'est révélée plus longue que ne le laissait

Fig. 2

Inscription de l'enceinte ouest du Temple du Rivage à Mahăbalipuram, viı' ${ }^{\mathrm{e}}$ siècle.

La dernière ligne se lit : sarvvalokamaheśam iśam.

Cliché : E. Francis.

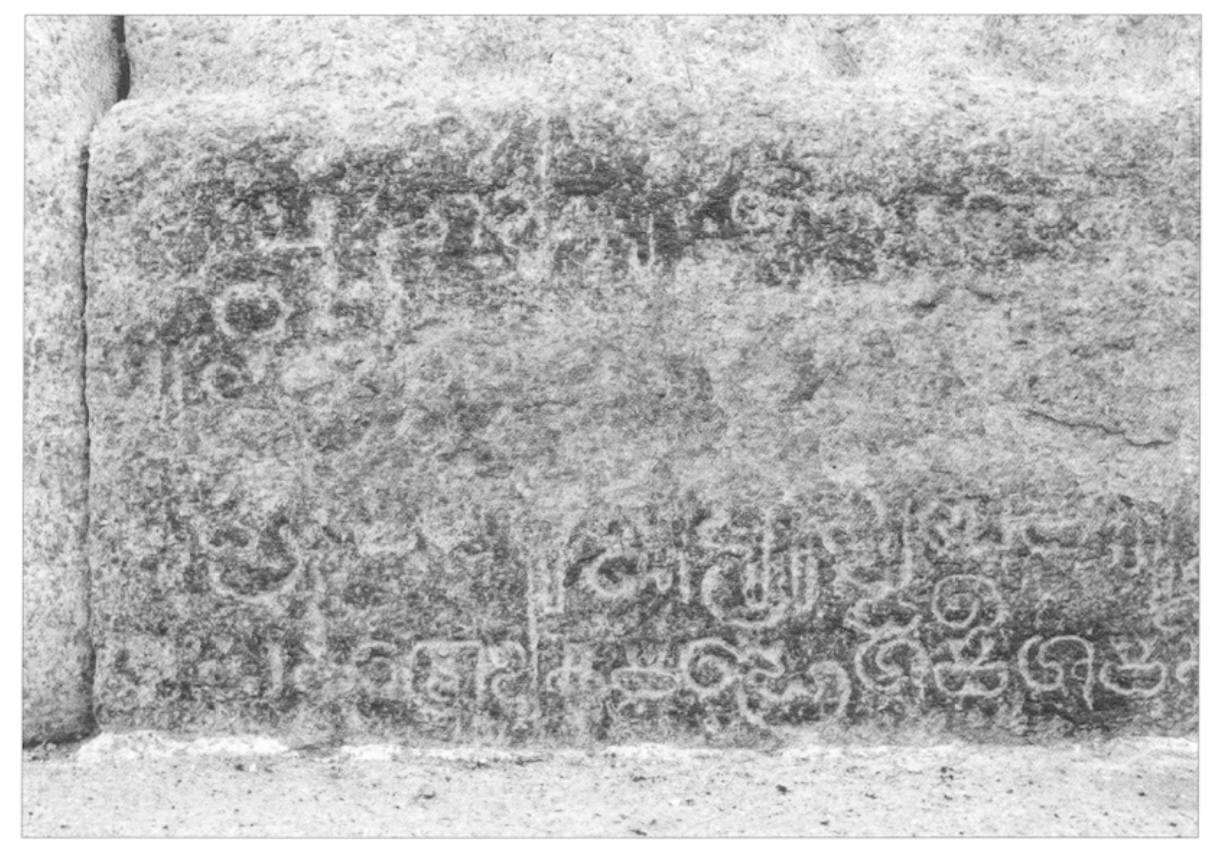

5. Citons également les tablettes trouvées à Peddamudiyam (K. V. Ramesh 1993) avec deux médaillons de cuivre incisés datés du vII siècle d'après le style, et, sur les marches du Mañgalatīrtha à Kāñoīpuram, en face du Śankarācāryamața, une demi-strophe attestée par ailleurs sur le Gaṇeśaratha et sur le Dharmarājamaṇụa à Mahābalipuram (M. Lockwood 2001 : 288).

6. Nous distinguons deux catégories d'inscriptions de la période des Pallava : les inscriptions royales (inscriptions des temples et tablettes de donation), et, d'autre part, les inscriptions locales en tamoul où la mention du roi se réduit généralement à l'utilisation de son année de règne pour la datation interne. Á confondre ces deux types d'inscriptions, on induit une omniprésence royale trompeuse. Pour des détails, voir E. Francis (en cours).

7. Cette inscription est de la même écriture que celle d'un des niveaux du soubassement des chapelles de la grande enceinte. 
supposer sa brève mention dans l' $A R E 1966-67$, p. 35 (inscription $\mathrm{n}^{\circ} 189$ ); or elle pourrait être importante pour dater les reliefs en surplomb et nous y reviendrons.

\section{De deux publications récentes}

On mentionnera d'abord Pallava Art de Michael Lockwood (2001), édition, révisée et augmentée, de deux ouvrages épuisés (M. Lockwood 1974 et 1982). Il s'agit là de la somme de ses travaux (personnels et en collaboration ${ }^{8}$ ) qui ont grandement fait avancer notre connaissance et notre compréhension de l'art, mais aussi de l'histoire et de l'idéologie de cette dynastie. Parmi ses découvertes importantes, on citera le caractère vishnouite originel de la grotte de Mahișāsuramardinī à Mahābalipuram, et le fait connexe que certains dvārapāla sont des āyudhapurusa de Śiva (7-20) ${ }^{9}$. M. Lockwood s'est aussi intéressé aux inscriptions et en a vérifié - fait suffisamment rare pour être remarqué - un nombre important ${ }^{10}$.

The Great Penance at Màmallapuram de Michael Rabe (2001), élaboration de son article de 1996, nous laisse plus sceptiques. Sa théorie d'un śleșa sculptural, représentant à la fois la descente du Gange et l'ascèse d'Arjuna, peine à nous convaincre, d'autant qu'elle donnc plus d'importance, nous semble-t-il, à la thèse "Arjuna " qu'à la thèse "Bhagîratha " ${ }^{1}$. Or nous continuons à croire que le thème central de la composition n'est pas tant l'ascèse que la présence de l'eau ${ }^{12}$. La Gañāa, venue du nord de l'Inde ${ }^{13}$ et du ciel, se constitue ici comme élément de vie, de rituel et de consécration royale. En tant que telle, elle fait sens dans l'ensemble de la production iconographique et épigraphique de la dynastie où la descente du Gange est très présente. La représentation du Govardhanadhara qui lui fait ici pendant, utilisant, comme elle, l'eau réelle qui se déversait à l'origine au-dessus du bas-relief, permet de mieux la

8. Gift Siromoney collabora avec M. Lockwood et publia beaucoup au sujet des Pallava. On trouvera sa bibliographie complète et le texte de ses articles sur la Toile (http://www.cmi.ac.in/gift). On lui doit notamment des études iconométriques des sculptures de nombreux monuments pallava. Concernant des périodes aussi brèves, nous nous méfierions cependant d'une application trop mécaniste d'un axiome méthodologique de l'histoire de l'art (l'évolution linéaire des motifs et du style).

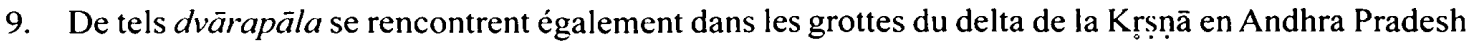
(à Bhairavakonḍa par exemple) et dans les grottes méridionales du Tamil Nadu associées aux Pānḍaa et aux Muttaraiyar. Voir D. Goodall et al (2005).

10. À la suite de R. Nagaswamy (1975), il signale notamment la lecture définitive śilāksarena à Trichy, que de nombreux commentateurs, se fiant à l'édition de E. Hultzsch (SII 1.33) qui lit śiläkharena, ont eu bien du mal à interpréter.

11. Rappelons, sans entrer dans les détails d'une controverse parfois fastidieuse, que l'ascèse d'Arjuna est l'interprétation locale accréditée dans les premières descriptions du site.

12. Pour plus de détails, voir E. Francis (en cours) et Ch. Schmid (2006).

13. La transposition de la géographie sacrée du nord de l'Inde dans le sud (voir R. H. Davis 1997 : 71-76), dans un royaume hindou considéré comme métonymie du monde, renforce, nous semble-t-il, la thèse « Bhagīratha ». 
comprendre ${ }^{14}$. L'iconographie pallava joue en effet souvent sur une complémentarité entre représentations shivaïtes et vishnouites, évidente au Temple du Rivage et au Kailāsanātha, shivaïtes. Elle se fait rivalité dans le vishnouite Vaikuṇthaperumāl, comme nous le verrons.

À Mahābalipuram, la descente du Gange s'inscrit dans ce type de complémentarité. Du point de vue des vishnouites ${ }^{15}$, la Gangā céleste porte le nom de Viṣnupadī, « Celle (qui a pour origine) le pied de Viṣnu », en un mythe dans lequel Trivikrama brise de son pied l'œuf de Brahmā. Cet épisode est représenté pour la première fois, à notre connaissance, dans la grotte de Varāha ouverte au dos du grand bas-relief, à une dizaine de mètres de la crête qui en marque le sommet : un Brahmā céleste y honore le pied levé de l'avatāra aux trois pas. La localisation de cette image l'inscrit dans l'ensemble iconographique, syncrétique, de la colline (fig. 3) : le Gange descendant sur terre grâce à Śiva et à la demande de Bhagīratha provient de l'œuf brisé par le pied d'un Viṣnu, dont il ne faut pas oublier qu'il est représenté dans un templion, à la base même du grand bas-relief.

Cette eau est aussi un élément du rituel de consécration royale, thème de prédilection de l'art pallava, représenté à Mahābalipuram par Krṣ̣na Govardhanadhara et Gajalakṣmī. À lire les chapitres 64-65 du Harivamśa, première version connue du soulèvement de la montagne, la conclusion est claire. À l'aide de cruches d'or, Indra consacre Krṣṇa, nouveau roi désigné comme Upendra. Quant aux Gajalakṣmī des grottes de Varāha et d'Ādivarāha, posant fermement les deux pieds sur le sol, écartant les jambes, levant leurs poings fermés à hauteur de poitrine et arrosées par les éléphants, elles adoptent la posture d'un roi trônant, comme ceux de la galerie du Vaikunțhaperumāl, consacrée à l'histoire des rois pallava. Cette posture, unique dans le corpus pourtant étendu de ce type de déesses, les signale, entre autres, comme des figures de la consécration du roi qu'évoquent les inscriptions de la grotte shivaïte de Cāluvarkuppam, du temple excavé qu'on appelle le ratha de Gaṇeśa et du Dharmarājamaṇạa : "Śańkara au beau visage repose sur le vaste étang qu'est sa tête [d'Atyantakāma, le roi fondateur du sanctuaire], qui est empli de l'eau du sacre, et où s'amassent les lotus que sont ses joyaux bigarrés $"{ }^{16}$.

De l'épigraphie du site à ces déesses qu'on arrose avec des jarres, à Krṣ̣na Govardhanadhara recevant l'onction des nuages qu'Indra commande ou à Śiva recevant le Gange dans ses mèches, l'eau se fait obsédante, symbole de la prospérité dont le roi qu'elle consacre se doit d'être le garant. Malgré ce désaccord important, on reconnaîtra la valeur de l'étude de $\mathrm{M}$. Rabe dans son approche du relief comme véhicule de l'idéologie royale.

14. Peu importe d'ailleurs que ces deux grands reliefs soient contemporains ou pas : l'un, probablement le Krṣna, est un calque de l'autre, ou plutôt l'équivalent dans un autre pan de la bhakti hindoue. Ils peuvent être séparés de plusieurs dizaines d'années, ce que confirmeraient les différences de style observables, mais il nous semble en tout cas clair qu'une image répond à l'autre.

15. Pour des références textuelles, on se reportera à Diana L. Eck 1982: 175, note 29.

16. Vers 2 de EI 10.1.23-24 et vers 9 de EI 10.1.20-21 : abhị̣ekajaläpürṇne citraratnämbujākare | āste viśăle sumukhạ sirassarasi śankarah ll. La strophe évoque la tête du roi Pallava, dans une image récurrente de la subordination qui consiste à placer sur sa tête les pieds d'un personnage révéré. 


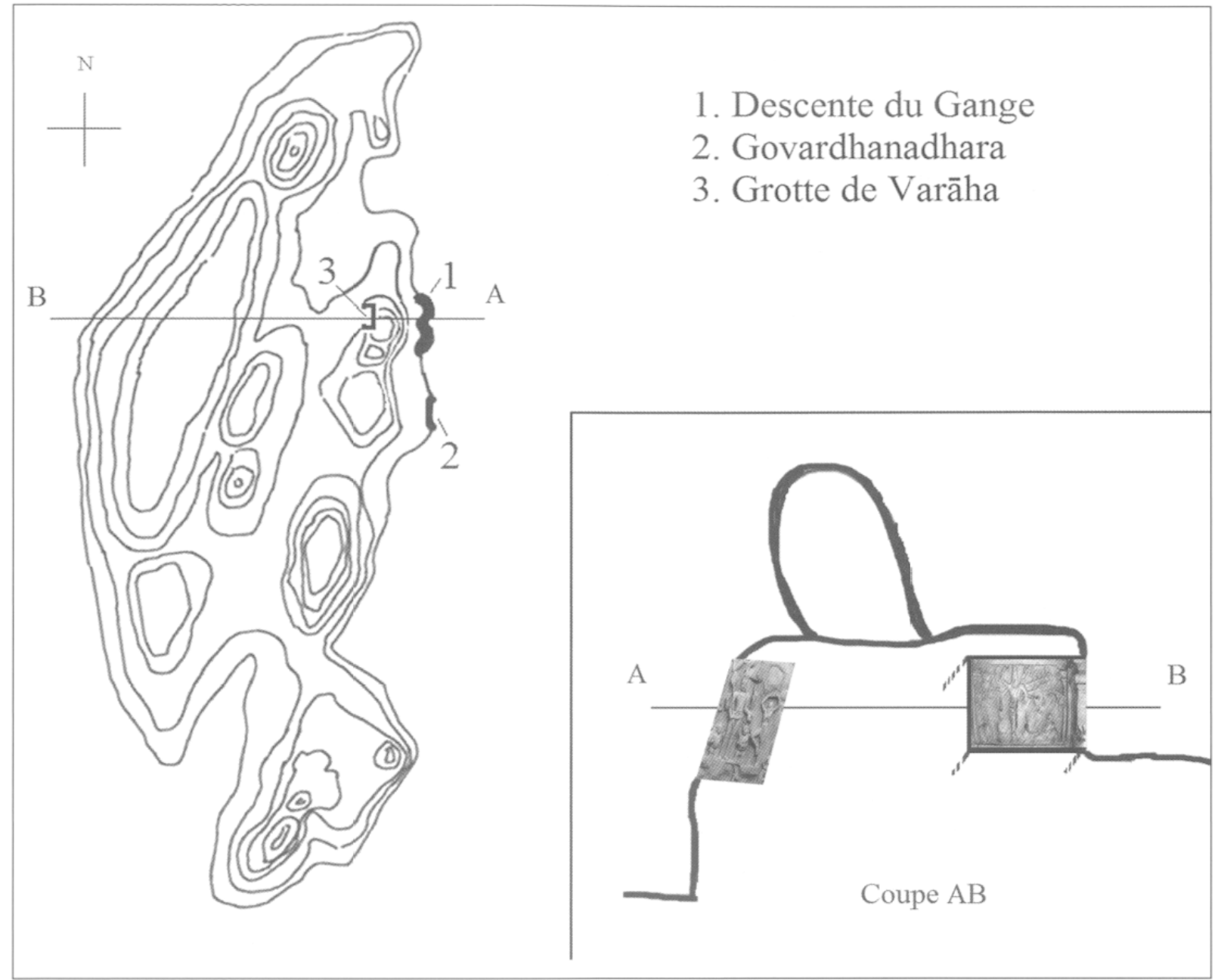

Fig. 3

Plan de situation de la Descente du Gange, du Krṣna Govardhanadhara et de la grotte de Varāha à Mahābalipuram. Plan : E. Francis.

\section{Le Temple du Rivage à Mahābalipuram}

Au début des années 1990, des fouilles ont mis au jour un bassin à gradins accolé à l'enceinte nord du Temple du Rivage (J. R. Marr 1991, W. Smith 1996, K. T. Narasimhan 1999, M. Lockwood 2001 : 223-233). Du sud au nord, on trouve d'abord un sanglier en ronde-bosse taillé à même le roc, la tête baissée dans la direction des lotus sculptés entre ses pattes. Il évoque l'Ādivarāha des mythes de création, c'est-à-dire le sanglier primordial retirant la terre du fond de l'océan, prototype de l'avatāra Varāha de Viṣnu. À noter qu'il aurait été sciemment brisé en morceaux, comme le laissent supposer des trous ménagés pour y introduire un levier. On rencontre ensuite un soubassement, taillé lui aussi à même le roc. Ce socle supporte un templion de même forme contenant une image que $M$. Lockwood identifia d'abord comme un Ardhanārīśvara avant d'en faire, erronément à notre avis, un Ardhanārīśvara Vīnādhara (2001 : 235-238). La présence de l'arc nous fait penser que la vinnă 
de Lockwood est en fait une flèche ${ }^{17}$. Ce qu'il prend pour sa caisse de résonance est en fait uniquement le sein de la moitié féminine. Cette image, avec d'autres, relève d'un type particulier d'Ardhanārīśvara guerrier - où la moitié masculine est armée de l'arc et d'un curieux trident pourvu également d'une lame de hache, et la moitié féminine d'une flèche, dont l'empennage est peut-être une réminiscence de son étendard de plumes de paon ${ }^{18}$ - dont ces représentations sont les premières connues ${ }^{19}$. Mais la difficulté principale pourrait être ailleurs. Le montage paraît factice : la pierre centrale ne s'ajuste pas exactement sur le socle et est d'une couleur différente. Ne s'agirait-il pas d'un réaménagement postérieur? Enfin, le bassin comporte un puits dont le cerclage de pierre, indépendant du rocher, porte l'image d'une femme à deux bras, encadrée par des porteurs de chasse-mouches. M. Lockwood (2001:226) y voit une figure royale, mais son siège végétal fait de lotus semblables à ceux qu'on voit entre les pattes du sanglier et la proximité même de ce Varāha, évoquent pour nous Bhū, la déesse Terre personnifiée, que l'avatāra retire du fond de l'océan, un mythe représenté dans la grotte de Varāha, sur la colline.

Ces découvertes confirment à notre avis le caractère vishnouite originel du temple du Rivage, reconnu par J. R. Marr (1991) et W. Smith (1996). Le noyau vishnouite ancien comprenait le Viṣnu couché, actuellement abrité dans un templion à l'ouest du temple shivaïte principal, encadré, au nord, par le bassin et, au sud, par le socle sculpté d'une gazelle et supportant un lion ${ }^{20}$. Tous ces éléments relèvent d'une même technique - la sculpture à même le roc qui rappelle celle des grottes et ratha excavés du site - et d'une même inspiration religieuse vishnouite : Nārāyaṇa est assoupi tandis que le sanglier fouille le fond de l'océan et que la Déesse parade avec sa gazelle et son lion ${ }^{21}$. Nous daterions dès lors ce noyau ancien dans la première moitié du VII ${ }^{\mathrm{e}}$ siècle, c'est-à-dire à l'époque des grottes du site. L'ensemble a pu fonctionner comme une recréation naturaliste du mythe : l'eau, remplissant périodiquement le bassin, engloutit la Bhū du puits tandis que Varāha plonge son museau dans les flots ; couché sur le rivage, Viṣnu dort en quelque sorte sur les eaux océanes.

17. Nous suivons là l'interprétation par Françoise L'Hernault ( $1975: 99$ et fig. 46) d'une image similaire provenant elle aussi du Temple du Rivage sur un énigmatique parallélépipède.

18. Cet étendard apparaît dès les premières représentations connues de la Tueuse de buffle. Voir Ch. Schmid (2003-2004: 11 ).

19. Le trident à la hache et l'empennage de la flèche sont bien visibles sur l'image analysée par F. L'Hernault, où Śiva est assis sur une banquette. D'autres exemples pallava, plus abîmés, où Śiva est assis sur Nandin, proviennent du Kailāsanātha (pièce détachée illustrée dans M. Lockwood [2001:236], aujourd'hui conservée dans la réserve de l'ASI à Mahābalipuram), de Mahābalipuram (n 109-38.39 du Madras Government Museum, de facture pallava évidente, où l'empennage est encore reconnaissable, publié par P. R. Srinivasan 1958-60) et de Tirukkalukkuñram. P. R. Srinivasan signale un exemple provenant de Kantiyūr, mais qui se révèle significativement différent.

20. Ce lion est peut-être un remplacement, peu ou prou postérieur, d'une sculpture du noyau vishnouite originel : il ne s'encastre pas exactement dans le socle.

21. Dans le sud de l'Inde, la Déesse est la sœur de Viṣnu, à qui elle est, exclusivement, associée dans les grottes de Mahābalipuram. Sur les images de la Déesse à Mahābalipuram, voir Ch. Schmid (2006). 
L'utilisation de l'eau comme élément de scénographie rapproche cet ensemble de la descente du Gange qui recourt également à cet élément naturel grâce au dispositif de la citerne (voir W. Smith 1998). Peut-être faut-il les penser comme contemporains? Le système iconographique originel ainsi reconstitué, comportant Viṣnu couché, Varāha et une forme particulière de Mahișāsuramardinī évoque le site gupta du Madhya Pradesh, Udayagiri, où l'importance de Viṣnu comme thème de l'iconographie royale est bien mise en valeur. Il s'agit là d'un rapprochement qu'il nous reste à explorer ${ }^{22}$.

Ce noyau vishnouite a subi par la suite des modifications importantes lors de la shivaïsation du complexe ${ }^{23}$, pour laquelle nous proposons, à titre d'hypothèse, le scénario suivant : le Viṣnu couché fut enclavé entre les deux temples de Śiva, et dans le bassin, le Varāha fut brisé en morceaux ${ }^{24}$, l'Ardhanārīśvara remplaça une image vishnouite dans le templion et le puits de Bhū fut recouvert peut-être par l'édicule que nous avons reconstitué (fig. 1c). Sous l'impulsion de quel roi? Le meilleur candidat nous semble Narasimhavarman II (700-725 environ), dont les inscriptions sur le socle du Varāha et sur le bord du bassin fonctionnent comme une signature ${ }^{25}$ et qui est le seul roi Pallava qu'on identifie dans les inscriptions du complexe.

Enfin, en divers endroits du complexe, on trouve des reliefs narratifs tantôt manifestement détachés (il manque alors leur portion inférieure), tantôt peut-être encore à leur emplacement initial, et relevant, semble-t-il, des aménagements postérieurs au noyau originel. M. Lockwood (1993: 98) est à notre connaissance le premier à les identifier comme des reliefs narratifs royaux, à l'instar des cent cinquante panneaux qui content l'histoire de la dynastie au Vaikuṇthaperumāl à Kāñcīpuram, sans détailler cependant son hypothèse d'interprétation. La comparaison de certains panneaux des deux sites est éloquente. On reconnaît clairement des scènes d'abhiṣeka

22. E. Francis remercie ici Claudine Bautze-Picron de lui avoir signalé les travaux de M. Willis sur ce site. Étudiant l'ensemble d'une thématique vishnouite associée aux éléments naturels dans un site " royal », M. Willis (2004: 50) note les ressemblances entrc lc sitc d'Udayagiri (Madhya Pradesh) et celui de Mahābalipuram. Voir aussi Ch. Schmid (2003-2004 : 34). La comparaison des deux sites nécessiterait une étude en soi.

23. Pour se convaincre que les rivalités sectaires font bien partie du contexte religieux de Mahābalipuram, rappelons entre autres la shivaïsation de la grotte de Mahisāsuramardin̄i, le vandalisme dont fut victime le Rāmānujamaṇdapa et la récurrence dans l'épigraphie d'un vers maudissant ceux dont Śiva n'habite pas le cœur. Pour les détails, voir E. Francis (en cours).

24. Contra M. Rabe (2001 : 132-133), pour qui la destruction du Varāha est l'œuvre des Cālukya, l'image évoquant leur soumission. L'association de Varāha aux Cālukya vishnouites est indéniable et expliquerait cette destruction, plus compréhensible, selon nous, de la part d'un Pallava shivaïte marquant ainsi non seulement son appartenance sectaire mais aussi sa supériorité sur ses rivaux Cālukya.

25. Contra M. Willis (2004: 50), pour qui les titres de Narasimhavarman II gravés sur le socle fonctionnent comme des légendes explicatives identifiant le roi à l'avatāra. Par ailleurs les hypothèses de M. Lockwood (2001 : 226, le templion circulaire comme linga, en corrélation avec le sanglier, et le puits comme yoni) et de M. Rabe (2001 : 131-132, le puits comme base d'un palidhvaja) nous semblent peu concluantes. 
royal ou des scènes figurant le roi au milieu de sa cour (fig. 4 et 5 , où l'on soulignera les caractéristiques communes suivantes : position du personnage central, de ses mains en particulier, présence des porteurs de chasse-mouches qui l'encadrent, échelle symbolique employée pour représenter le roi comme plus grand que les autres personnages). Les reliefs narratifs détachés proviennent vraisemblablement de galeries à portiques en ruine, sur les enceintes nord et sud, où l'on distingue dans le bas des murs leurs possibles portions inférieures. Quant à ceux qui semblent à leur emplacement originel sur l'enceinte ouest, on les liera à l'inscription qu'ils surplombent ( $A R E$ 1966-67 : 35 , inscription $n^{\circ} 189$, évoquée ci-dessus). Sa paléographie et son contenu lisible nous la font attribuer à Narasiṃhavarman II ${ }^{26}$. Le Temple du Rivage livrerait ainsi le premier exemple d'un ensemble de reliefs narratifs royaux, et Narasimhavarman II se poserait dès lors en précurseur de Nandivarman II au Vaikuṇthaperumāl .

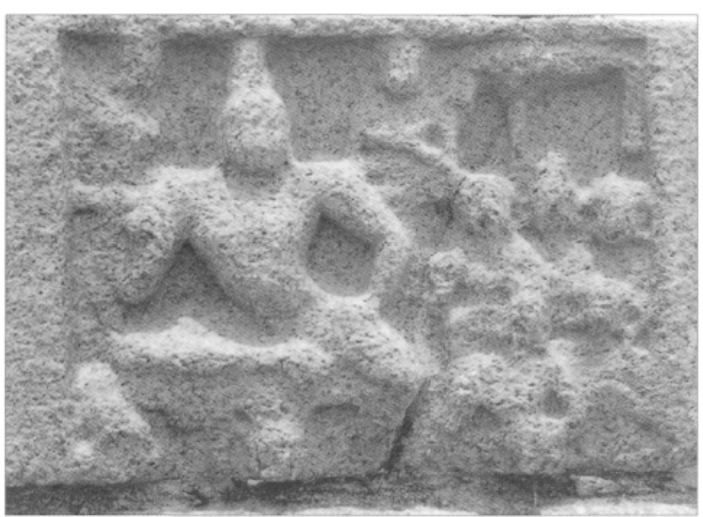

Fig. 4

Scène de cour, Temple du Rivage,

Mahābalipuram, viII ${ }^{\mathrm{e}}$ siècle.

Cliché : E. Francis.

Fig. 5

Scène de cour, reliefs narratifs royaux, Vaikuṇthaperumā!, Kāñcĩpuram, Ix ${ }^{\mathbf{e}}$ siècle. Cliché : E. Francis.

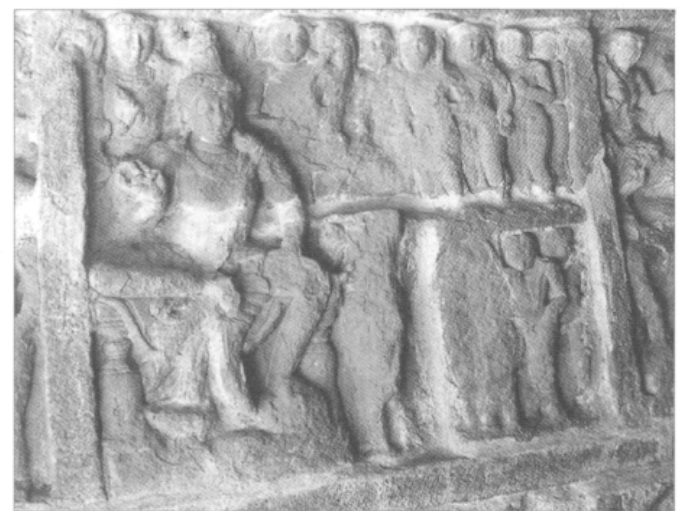

L'organisation vishnouite originelle du complexe du Temple du Rivage fut donc profondément modifiée par le mouvement shivaïte. Les inscriptions pallava du site nous font attribuer cette transformation à Narasimhavarman II exclusivement, tandis que l'analyse architecturale de J. Dumarçay (1975:28) indique des étapes successives dans le réaménagement du complexe ${ }^{27}$.

26. On y lit notamment [...] s[i] mhhah [ll] śrimaheśvaracūlamanih. Ce biruda évoque d'autres de ses titres signifiant semblablement que Śiva est son diadème. Cette image de subordination à la divinité est de celles que nous évoquons en note 16. Le parallèle est frappant avec l'inscription du chapiteau de colonne gravé entre autres titres de śrinarendrasimhạ || śrimaheśvara[candra?] cülāmanih || et attribuée de manière convaincante à Narasiṃhavarman II (voir M. Lockwood 2001 : 263-265). Il est significatif que dans ces deux cas śrì soit en caractères « năgarī » alors que le reste de l'inscription est en caractères grantha, mélange d'alphabets que l'on retrouve au Kailāsanātha.

27. J. Dumarçay propose d'attribuer le petit temple de Śiva à Narasiṃhavarman II et le grand à Nandivarman II. Nous n'excluons pas, pour notre part, que Narasiṃhavarman II soit intervenu à différents moments de son règne sur le complexe. 


\section{Le Kailāsanātha à Kāñcīpuram.}

Le Temple du Rivage est l'un des premiers temples construits en pierre du Tonțaimantalam. Sa phase qu'on peut appeler shivaïte, par opposition à son noyau vishnouite ancien, est à peu près contemporaine de l'érection du plus fameux des temples pallava, le Kailāsanātha de Kāñcīpuram, la capitale dynastique, où sont rassemblés la plupart des temples royaux construits. Ce temple fondé par Narasiṃhavarman II doit sa célébrité à la beauté de son épigraphie et de son iconographie, qui s'avèrent aussi profondément originales. L'une des écritures ornementales utilisées est une « nāgarī » méridionale d'un type unique et l'ensemble nous apparaît comme un lieu d'expériences iconographiques. C'est là qu'on rencontre pour la première fois de leur histoire de nombreuses représentations shivaiites, qui ne sont jamais illustrées dans le nord de l'Inde et ne l'avaient encore jamais été dans l'Inde méridionale. La créativité pallava se marque alors essentiellement dans le domaine d'un narratif que les imagiers nord-indiens n'ont guère exploité. Le linga est la représentation par excellence de Śiva en Inde septentrionale pendant la période gupta ${ }^{28}$, mais la controverse à propos de l'existence même de linga dans les sanctuaires pallava est toujours d'actualité ${ }^{29}$. Au Kailāsanātha où les représentations de Śiva abondent (sur les façades du sanctuaire principal, sur la grande enceinte de cinquante-huit chapelles ${ }^{30}$, sur le Mahendravarmeśvaragrha et sa petite enceinte à l'entrée ${ }^{31}$, ainsi quc sur lcs huit chapelles extérieures), s'organise un ensemble de figures nouvelles jouant sur les directions, les oppositions et les juxtapositions pour révéler les différents aspects du dieu Śiva.

Les images du sanctuaire principal se répartissent en trois catégories selon les trois directions, sud, ouest et nord de ce temple s'ouvrant à l'est. La façade sud est

\footnotetext{
28. Les représentations shivaïtes narratives existaient cependant. Nous trouvons des représentations gupta du Kirātārjunīya suivi de la remise de l'arme pāślupata, de Śiva recevant le Gange dans l'une de ses mèches, de Rāvaṇa soulevant le mont Kailāsa et de Śiva dansant. Des représentations de temples d'Orissa du $v^{\mathfrak{e}}$ ou du $\mathrm{vII}^{\mathfrak{e}}$ siècle reprennent les thèmes du Śiva mendiant et du Śiva dansant. Cependant, il faut constater que ces représcntations sont relativement rares et n'occupent pas les façades des temples, mais des médaillons ou le haut de piliers, contrairement aux grottes et temples vishnouites qui voient très rapidement se développer une iconographie narrative : Varāha, Trivikrama, Viṣnu dormant sur Śeșa, Gajendramokṣa et Mahișāsuramardin̄̄, entre autres.
}

29. L'espace manque pour exposer les arguments de cette controverse, mais nous ne manquerons pas de faire le point dans un ou plusieurs travaux ultérieurs (E. Francis, en cours). Signalons simplement ici que, pour nous, il n'est pas exclu que l'inscription de Mahendravarman ${ }^{\text {er }}$ dans sa grotte à Trichy fasse allusion à un linga, installé dans la cella mais aujourd'hui disparu.

30. Ces chapelles s'ouvrent vers l'est et leur mur latéral, tourné vers l'intérieur du complexe, est sculpté d'un panneau. Face aux côtés du vimāna, deux chapelles sont plus grandes : celle de Brahmā au sud et celle de Viṣnu au nord. L'espace muré, qui sépare les chapelles, est scandé par des panneaux plus petits, où un personnage féminin occupe une place récurrente. Enfin les couronnements même de ces cinquante-huit chapelles portent une représentation sur la face de l'octogone tourné vers l'intérieur du complexe.

31. La petite enceinte du Mahendravarmeśvaragrha interrompt la grande enceinte en s'y appuyant et masque l'arrière de certaines des chapelles extérieures. Tout ceci prouve assez que le Mahendravarmeśvaragrarha est postérieur au Rājasiṃheśvaragṛha. 
consacrée aux formes bénéfiques de Siva, proche du monde des humains, s'inspirant notamment de l'iconographie bouddhique ${ }^{32}$; cette direction semble s'orienter déjà vers une thématique dominante de la connaissance, telle que l'étude d'un temple du premier art cōla par Ch. Schmid l'a mise en évidence (supra, dans ce même BEFEO, p. 78-84).

Deux des représentations de la façade ouest sont des Śiva dansants. Le premier dans le sens de la pradaksinā adopte une posture agenouillée propre aux Pallava rappelant celle des personnages volants et désignée généralement comme àlìdha. Venant ici à la suite du Bhikșātanamūrti de la face sud, elle nous paraît associée au Śiva mendiant, errant dans bois et villages, un crâne à la main, et se mettant soudainement à danser (voir Têvāram I.67.4, III.19.7, III.45.4, VII.98.1) ${ }^{33}$. Mais ce dieu, qualifié de fou, danse surtout la nuit dans les champs de crémation, à la lueur des bûchers, tenant en main un tison enflammé (voir les deux « Dizains » de Kāraikkālammaiyār et Têvāram I.20.4, I.98.7). La danse est ici figure de destruction et de mort ${ }^{34}$; son aspect victorieux nous semble plus apparent avec le second Śiva dansant. Ce dernier est habituellement qualifié d'ürdhvatạndava: le dieu y lève une jambe à la verticale dans une posture similaire à celle de l'avatāra Trivikrama, le conquérant des trois mondes.

Ces deux images de la danse marquent opportunément la transition entre le Śiva mendiant, ascète et enseignant de la face sud, et le Śiva victorieux de la face septentrionale. Là, les images mettent en scène un dieu qui, s'incarnant afin de sauver un monde en péril, représente l'une des fonctions essentielles du roi guerrier, conquérant et protecteur ${ }^{35}$. Nombre de déesses guerrières l'accompagnent dans ses combats, la terrible Kālī, la Korravai du Cilappatikāram, Jyeșthā la déesse de mauvais augure, représentée sans doute ici pour la première fois de son histoire, et, enfin, la déesse au lion, guerrière pallava qu'on retrouve cinq fois dans le complexe, toujours face au nord comme le seront les figures de déesses armées foulant la tête coupée du buffle dans les temples cōla. La quasi-absence au Kailāsanātha de celle qu'on appelle Mahișāsuramardin̄i, la Tueuse du buffle, n'en est que plus remarquable et attire notre attention sur l'évolution qui se fait jour entre les monuments excavés de Mahābalipuram, où elle est si présente, et les premiers temples pallava construits où la déesse armée accompagnée de son lion lui dame le pion.

32. Dans l'ordre de la pradaksināa : Śiva et Pārvatī en couple (deux panneaux), Dakṣināmūrti, Lingodbhavamūrti, Bhikṣātanamamưrti.

33. Les relations entre le Śiva mendiant et cette forme de danse, aussi bien dans les temples construits pallava que dans les textes, sont étudiées par V. Gillet (2006 : 109 sq.).

34. Sur la signification du Națarāja à la période cōla, on lira P. Kaimal (1999), contra A. K. Coomaraswamy. Elle souligne son aspect destructeur qu'elle rapporte à un dieu tamoul terrible, maître du champ de crémation et de la mort. L'association de la danse avec la victoire est par ailleurs amplement attestée : voir Cilappatikäram VI.40-70, Mayamata 80a (B. Dagens 1976 : 392).

35. Il s'agit des images suivantes, dans l'ordre de la circumambulation : Kalārimūrti, Tripurāntakamūrti, Jalandharasạ̣hāramūrti, la déesse armée au lion et Gañgādhara. 
Les figures de l'enceinte qui entourent le sanctuaire d'un écrin de cinquante-huit chapelles confirment la spécificité thématique des directions. Face au nord, sur le mur sud, prennent place les figures actives, armées ou combattantes des dieux : la déesse armée accompagnée de son lion, les Mātṛkā, les avatāra de Viṣnu et des formes combattantes de Śiva. Face au sud, sur le mur nord, les formes apaisées d'un Śiva dispensateur de grâce dominent. Il ne nous semble pas, en revanche, que les figures féminines qui se répètent entre les chapelles, femmes assises dans un environnement montagneux variant légèrement d'une représentation à l'autre, suffisent à faire du Kailāsanātha un temple dédié aux yoginī, dont l'enceinte symboliserait la yoni et le sanctuaire central, le linga. Quelque séduisante que soit cette hypothèse de Padma Kaimal (2005), il nous paraît très difficile de la suivre notamment dans son dénombrement de soixante-quatre chapelles (voir sa note 8 , page 57 ). Nous n'en voyons que cinquante-huit, entre lesquelles on ne rencontre d'ailleurs pas que des figures de déesses ${ }^{36}$. On peut se demander si l'auteur, fascinée comme d'autres par l'histoire de la Déesse, n'exagère pas son importance dans l'histoire religieuse ancienne de Kāñcīpuram. Ne projette-t-on pas ainsi dans un passé trop ancien une Déesse Kāmākṣī dont rien n'atteste l'existence, à notre connaissance, à l'époque des Pallava ? Néanmoins, P. Kaimal relève l'opposition entre les formes non mariées de la Déesse (aux bras multiples, guerrières, combattantes, accompagnées du lion ou le chevauchant, orientées vers le nord) et les formes mariées (à deux bras, apaisées et orientées vers le sud). Ces échos iconographiques qu'elle met en valeur nous paraissent construire en effet un réseau symbolique, dont il faut tenir compte en particulier pour expliquer l'iconographie du mandapa, exclusivement consacré à des divinités féminines.

La complexité du réseau iconographique ${ }^{37}$ sur le sanctuaire même est illustrée, à notre sens, par deux des créations iconographiques pallava, Dakṣināamūrti et Jalandharasaṃhāramūrti, qui occupent, respectivement, le centre des faces sud et nord. Le destin de ces images est très différent. Dakṣināmūrti, le dieu qui enseigne assis sous un banian, placé toujours au sud des temples shivaïtes méridionaux, est encore aujourd'hui l'une des formes les plus populaires de Śiva. Au contraire, Jalandharasamhāramūrti disparaît quasiment après les Pallava ${ }^{38}$. Pourtant, dès leur apparition, qui pourrait bien avoir eu lieu au Kailāsanātha, les deux formes se répondent ; cette complémentarité suscite les commentaires suivants.

36. Aux enceintes est et ouest on rencontre, entre les chapelles, exclusivement des couples assis (où les personnages ont deux bras). Aux enceintes sud et nord, R. Nagaswamy (1969: 13) identifie des dikpāla. A l'intérieur des chapelles, on trouve essentiellement des Somāskanda, peints ou sculptés.

37. Pour une étude détaillée du programme iconographique du Kailāsanātha, voir V. Gillet (2006 : 267 sq.).

38. V. Gillet a identifié un Jalandharasaṃhāramürti sur un petit relief du soubassement du temple de Śivayoganātha à Tiruvicallūr, situé à une dizaine de kilomètres à l'est de Kumpakōnam et daté du $\mathrm{Xl}^{\mathrm{e}}$ siècle. C'est la seule image postérieure aux Pallava que nous connaissons. Elle illustre d'ailleurs le mythe selon des modalités iconographiques assez différentes. 
Hans Bakker (2001 et 2004) a retracé l'histoire du concept de Śiva enseignant dans les textes sanskrits ${ }^{39}$. Face à sa réflexion, nous voudrions présenter ce qu'on pourrait appeler, en quelque sorte, le point de vue des images, inscrites dans une tradition méridionale. Le Śiva que les āgama appellent Dakṣināmūrti est assis sous un arbre. Il a quatre bras, porte le rosaire et la torche (fig. 6). À ses pieds, quatre sages l'écoutent. Des gazelles sont assises au bas du relief et des lions encadrent la représentation. Ce type de composition se retrouve dans les illustrations, beaucoup plus anciennes, du premier sermon que le Bouddha délivra dans le parc aux gazelles de Sārnāth. L'emprunt iconographique à un bouddhisme florissant alors à Kāñcīpuram, fermement combattu par les autres mouvements religieux ${ }^{40}$, est manifeste. Il n'est cependant qu'un des éléments qui expliquent cette forme de Śiva. Le dieu au banian pourrait aussi plonger ses racines dans une tradition attestée dans la littérature tamoule ancienne. Le poème 87 du Kuruntokai évoque une divinité terrible habitant l'arbre de la communauté. On connaît également dans le Puranān̄ūru (198.9-10) āl amar celvan, « Le Fortuné associé à l'arbre banian ", qui, dans le Cilappatikāram (XXIII.90-95 et XXIV.2-3), le Manimēkalai (III.144-145) et le Kalittokai (81, 83 et 133), est également le père de Murukan. Enfin le dieu à l'arbre banian enseignant aux quatre sages apparaît de façon récurrente dans les hymnes du Tēvāram (par exemple I.132.1). En résumé, nous pourrions dire que Śiva, figure de l'enseignement assimilant un dieu tamoul au banian, serait représenté en s'inspirant de l'image du Bouddha ${ }^{41}$.

Ce dieu pourrait par ailleurs s'intégrer plus précisément, au moment de son apparition, dans le mouvement du Śaiva-Siddhānta, dont l'une des toutes premières attestations épigraphiques se trouve au Kailāsanātha. On sait toute l'importance des rites d'initiation dans ce mouvement. L'inscription de fondation du Rājasiṃheśvara, le sanctuaire principal du Kailāsanātha, mentionne explicitement l'initiation saiddhāntika de Narasiṃhavarman II, son bâtisseur ${ }^{42}$. Selon les traités de cette école, le maître brûle les doigts de son disciple à l'aide d'une torche en un rituel d'initiation qui vise à le débarrasser de son impureté (mala- $)^{43}$. L'inscription du Kailāsanātha évoque la disparition de cette impureté ( $k$ satasakalamalo) pour ce roi qui emprunte la voie du Śaiva-Siddhānta (śaivasiddhāntamārge). Ce Dakṣināmūrti qui porte la torche sur la

39. Sur les Dakṣināmūrti cōla, voir Ch. Schmid (supra dans ce même volume du BEFEO, p. 94-97).

40. Sur l'importance du bouddhisme et du jaïnisme à cette époque au Tamil Nadu, voir le témoignage du pèlerin chinois Xuanzang en visite à Kāñcīpuram vers 640, la diffamation des sectes bouddhistes et jaïnes dans les hymnes du Tēvāram, ou encore les nombreuses sculptures bouddhistes et jaïnes qui essaiment le pays tamoul, dont certaines pourraient dater de la période des Pallava.

41. Les rapports entre iconographie de Śiva et du Bouddha sont traités en détail par V. Gillet (2006 : $80 s q ., 164 s q$. entre autres).

42. SII 1.24, vers 5cd : sakti(h)ksunnärivarggo viditabahu-nayaśs śaivasiddhāntamārgge śrimāan atyantakāma[h*] ksatasakalamalo dhürddharặ pallavānām. Voir aussi D. Goodall (2004 : xix, note 17) qui donne à tout l'hémistiche une signification saiddhāntika.

43. Mrgendrāgama, Kriyāpāda 8.213-214a, par exemple. Notons que le mouvement pāśupata pourvoit son guru, Lakulīśa, d'une torche dans la main gauche mais sans en préciser l'usage (Skandapurāna 167 , 127 ; P. Bisschop $2006: 69$ [synopsis], 128 [texte]). 


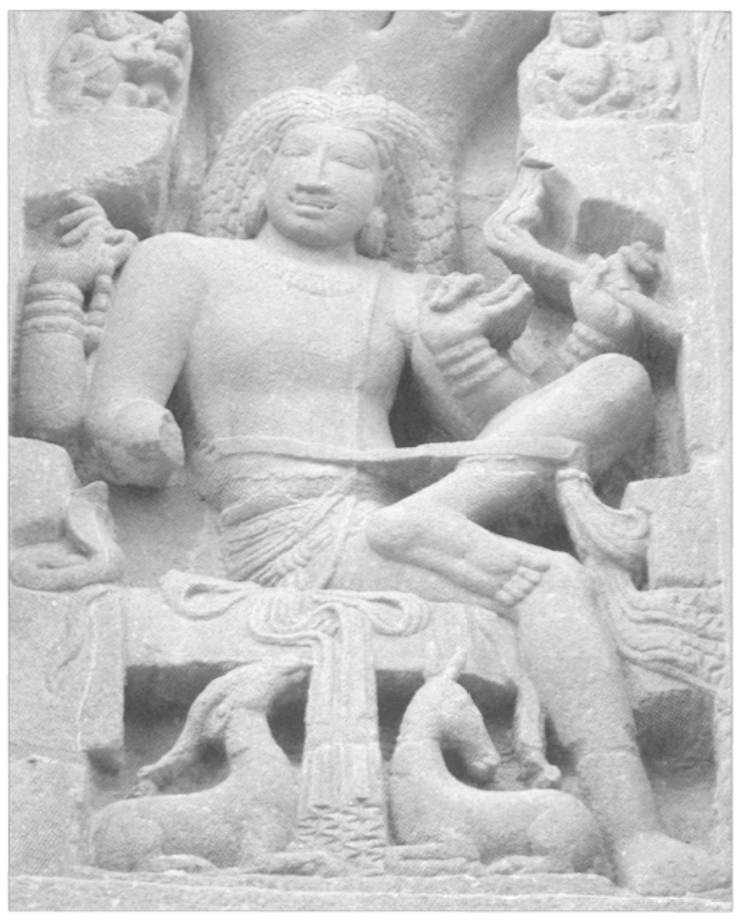

Fig. 6

Dakṣiṇāmūrti, vimāna, face sud, Rājasiṃheśvara au Kailāsanātha, Kãñīīpuram, vIII ${ }^{\mathrm{e}}$ siècle.

Cliché : E. Francis.

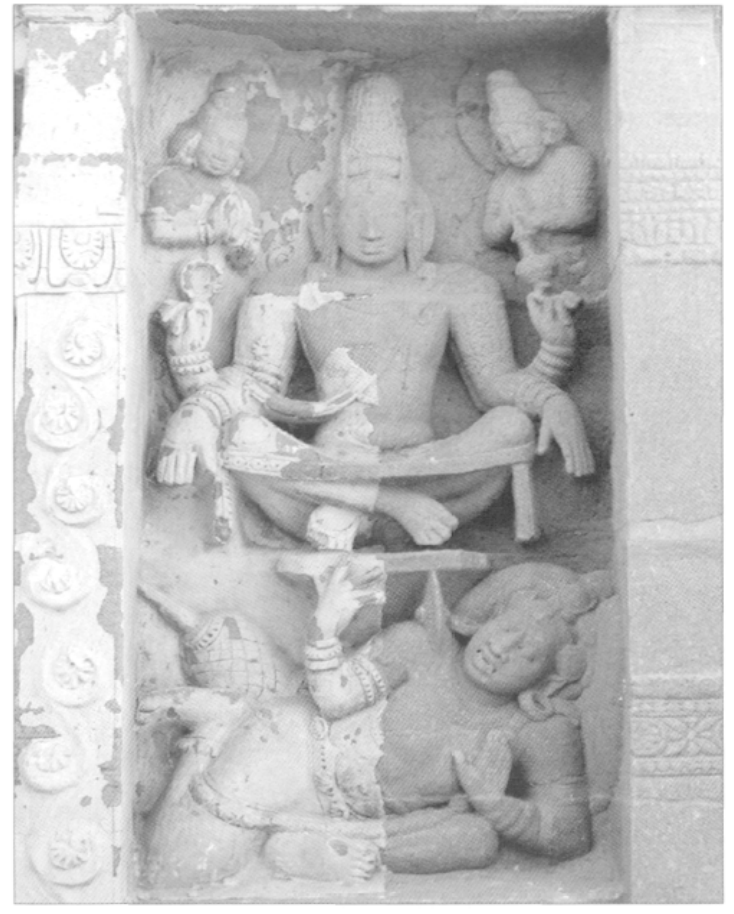

Fig. 7

Jalandharasaṃhăramūrti, vimāna, face nord, Rājasiṃheśvara au Kailāsanātha, Kãñīpuram, vIII ${ }^{\mathbf{e}}$ siècle.

Cliché : K. Kataoka.

première face de la pradakșinā ne serait-il pas une figure de guru saiddhāntika purifiant par le feu son disciple au début d'un chemin initiatique dont la circumambulation du temple serait la métaphore ${ }^{44}$ ?

Au Dakșināmūrti de la face sud répond Śiva terrassant le démon Jalandhara, sur la face nord (fig. 7). La posture du dieu, assis dans la partie supérieure du panneau, les jambes serrées par un yogapatta, et ses attributs ascétiques, rosaire et vase à eau, expliquent les identifications, à notre sens erronées, comme Dakșināmūrti, Śiva yogin ou Kāmāri ${ }^{45}$. Le démon de la partie inférieure - yeux globuleux, cheveux défaits,

44. L'hypothèse ici formulée requiert une étude approfondie de l'insertion de la figure du dieu enseignant dans d'autres temples ; elle fonctionne bien pour les temples ouvrant à l'est, en particulier pour le Kailāsanātha. Or une bonne partie des temples pallava shivaïtes ouvrent à l'ouest, Dakṣināmūrti se trouvant alors placé en fin de circumambulation. Peut-être faut-il alors concevoir l'initiation comme conclusion de celle-ci?

45. F. L'Hernault identifie ces images comme Dakṣināmūrti, vu sa complémentarité avec celui de la face sud (1975: 106 et fig. 51), puis comme Śiva yogin (1978:107-108). Édith Parlier-Renault (2000) y voit un Kāmāri. R. Nagaswamy (1969:23) identifie comme Jalandharavada le panneau de la chapelle $\mathrm{n}^{\circ} 18$ de la grande enceinte (Śiva protégeant les serpents de Garuda, voir V. Gillet 2006 : 282-sq.) alors qu'il se trouve sur la chapelle $n^{\circ} 17$. Dans d'autres publications il se contente de signaler son existence dans l'art pallava (1978:29) et identifie correctement le panneau de la face nord du vimāna du Kailasānatha, mais sans plus de précision dans le texte de son article (1988 : fig. 27). Voir aussi K. V. Raman et B. Sasi Sckaran (1992), plus détaillés. 
écrasé par le dieu - permet d'identifier l'image : un disque, vu de profil, est planté dans son épaule. Dans les Purāna et le Têvāram, Śiva anéantit le démon Jalandhara en le défiant de soulever le disque qu'il trace de son orteil à la surface de la terre ou de l'eau, selon les versions; quand Jalandhara saisit le disque, celui-ci se met à tourner et, se fichant dans son épaule, coupe son corps en deux ${ }^{46}$. Les textes ne rendent cependant pas compte de certains détails de l'image, en particulier du caractère ascétique de Śiva. Pourrait-il s'expliquer par sa complémentarité avec la représentation du dieu au banian, systématique dans les temples royaux pallava construits, dans la perspective d'un emprunt à l'iconographie bouddhique? Le disque représenté de profil au centre du Jalandharasamhāramūrti, absent dans le Dakṣiṇāmūrti - deux images où Śiva enseigne ou médite -, si présent dans les représentations du sermon du Bouddha dont s'inspire le Dakṣiṇāmūrti, n'évoqueraitil pas le cakra bouddhique? La lutte contre un démon, rappelle cet autre épisode célèbre qu'est la lutte de Bouddha, immobile en méditation, contre Māra. Par ailleurs le disque renvoie également au cakra de Viṣnu, dont c'est un attribut essentiel. La représentation du don du disque par Śiva à Viṣnu est d'ailleurs courante dans les temples pallava et apparaît au Kailāsanātha, sur la grande enceinte, presque en face du Jalandharasaṃhāramūrti.

Sur la face sud du vimāna du Kailāsanātha, la Lingodbhavamūrti fait aussi une de ses premières apparitions. Śiva sous forme humaine s'inscrit à l'intérieur d'une colonne de feu qui représente son linga. Avec cette image on assiste au passage du symbole à la figure, en d'autres termes à l'incarnation de la divinité. Dissipant les ténèbres qui empêchent Brahmā et Viṣnu de le reconnaître comme dieu suprême, Śiva se révèle sous forme humaine comme en une initiation. Ici aussi l'iconographie semble s'inspirer d'un modèle bouddhique. Au début de notre ère, à Amarāvatī, aux marges septentrionales d'une région d'où proviennent plusieurs tablettes pallava des $\mathrm{IV}^{\mathrm{e}}$ et $\mathrm{V}^{\mathrm{e}}$ siècles, Bouddha est parfois représenté comme une colonne de feu adorée par ses dévots ${ }^{47}$. La Lingodbhavamūrti serait donc en partie le résultat, comme Śiva Dakṣināmūrti, d'un emprunt au bouddhisme. Comme pour confirmer ce rapprochement entre deux manifestations de la vérité suprême, la Lingodbhavamūrti suit de près Śiva Dakṣināmūrti, dans le sens de la circumambulation du Kailāsanātha. Les éléments communs à ces deux formes mettent, nous semble-t-il, l'accent sur des éléments importants de l'iconographie shivaïte pallava: le feu, l'apparition humaine de la divinité, l'initiation et le parallèle bouddhique.

Les images de Śiva au Kailāsanātha nous semblent donc illustrer délibérément la supériorité de Śiva sur d'autres dieux - Viṣnu, le Bouddha ou même des divinités

46. Voir Śivapurāna (Rudrasamhitā, Yuddhakhanda 5.13-26 et Śatarudrasamhitā 30), Padmapurāna (Uttarakhaṇ̣a, 3-18 et 96-104), Lingapurāna (I.97), Tēvāram (III.113.2, III.122.2, VI.53.2, VII.98.5).

47. Voir A. K. Coomaraswamy (1935: 10 et fig. 4-10) qui rapporte ces représentations bouddhiques à l'Agni védique. 
jaïnes dont certaines images sont proches de celles du premier sermon du Bouddhadans une complémentarité où se répondent formes divines armées du mur nord et formes apaisées du mur sud ${ }^{48}$. Une telle organisation du programme iconographique trouve dans le Vaikuṇthaperumāl, pourtant vishnouite et ouvrant à l'ouest, une forme de confirmation.

\section{Le Vaikuṇthaperumā!}

De sa galerie de reliefs illustrant les règnes de souverains Pallava, dont beaucoup sont toujours impossibles à identifier, à son sanctuaire lui-même habité de formes de Viṣnu qu'on ne rencontre jamais ailleurs, le Vaikunththaperumāl, vraisemblablement fondé ou à tout le moins achevé par Nandivarman II (825-900 environ), reste d'interprétation difficile.

La galerie de bas-reliefs narratifs royaux qui l'enserre et raconte l'histoire de la dynastie des origines jusqu'à Nandivarman II constitue plus proprement une " praśasti in figures ", pour reprendre le titre de M. Rabe (1996) à propos du grand relief de Mahābalipuram. La série commence en effet par les huit ancêtres mythiques de la dynastie, puis vient la naissance de l'éponyme Pallava avant que ne s'égrènent les règnes des rois successifs. La correspondance avec la structure même des praśasti épigraphiques est remarquable. S'il est bien difficile de faire coïncider exactement les détails des panneaux du temple avec le texte d'aucune praśasti pallava connue, cette impossibilité rapproche encore les représentations de la galerie des éloges épigraphiques, qui sont, en effet, souvent différents les uns des autres. La galerie du Vaikuṇthaperumāl se présente donc en définitive comme une autre praśasti, mais ici l'éloge royal se fait image.

L'aile sud de la galerie, où les panneaux font face au nord, entretient justement un lien particulier avec les inscriptions. C'est le seul endroit de la galerie où l'on en trouve, sous forme de légendes explicatives en tamoul inscrites sur le bandeau de granit horizontal qui sépare les deux séries superposées de panneaux ${ }^{49}$. L'ensemble reste cependant très difficile d'interprétation. Lors d'une mission de l'EFEO en 2004, nous nous sommes rendu compte que certains de ces panneaux narratifs, composés chacun de différents morceaux, avaient à l'évidence été reconstitués de manière

48. On fera remarquer cependant que Śiva au Kailāsanātha est régulièrement pourvu de crocs terribles, même dans ses formes censément apaisées (Dakșināmūrti par exemple, fig. 8). Cette caractéristique requiert un examen plus approfondi, qui devra rendre compte également du fait qu'un crâne apparaît dans la coiffure des Dakṣināmūrti postérieurs aux Pallava.

49. Les légendes, qui concernent uniquement, semble-t-il, la série supérieure de panneaux, se terminent généralement par itam, «lieu, place », précédé d'un participe relatif. L'expression est à comprendre littéralement comme « lieu, endroit où ... »; transposée en français, elle correspond au « Où ... » qui commence les chapitres de romans policiers, comme ceux de Gaston Leroux. Nous souscrivions donc par avance aux propos de Jean-Luc Chevillard (journée « épigraphie tamoule ", EPHE, avril 2005), similaires jusqu'à l'exemple du roman policier, nous souvient-il. Pour les détails concernant le corpus épigraphique et les reliefs narratifs du temple, voir E. Francis (en cours). 
absurde (fig. 8a-b-c où $8 \mathrm{a}$ et b montrent les panneaux en l'état tandis que $8 \mathrm{c}$ est un montage plaquant une partie de $8 \mathrm{~b}$, portion claire, sur $8 \mathrm{a}$, portion foncée) ${ }^{50}$. Ce réassemblage incohérent eut lieu, en tout cas, avant 1909, date de la publication par Alexander Rea de croquis qui montrent les panneaux tels qu'on peut les observer in situ aujourd'hui. Aucune des études publiées jusqu'ici, dont celle de C. Minakshi (1941), ne font état du désordre des représentations mais elles se proposent de donner un sens à ce qui n'en a pas tel qu'il se présente actuellement. Il faut pour comprendre la logique de la narration du règne de Nandivarman II, à qui cette partie de la galerie est consacrée, remettre les bas-reliefs en ordre, et peut-être aussi l'inscription, le bandeau qui la porte étant lui aussi formé de morceaux. Nous avons repéré quelques fragments de panneaux manifestement déplacés, mais il s'agit là d'un travail dont il ne faut sous-estimer ni la difficulté ni la longueur.

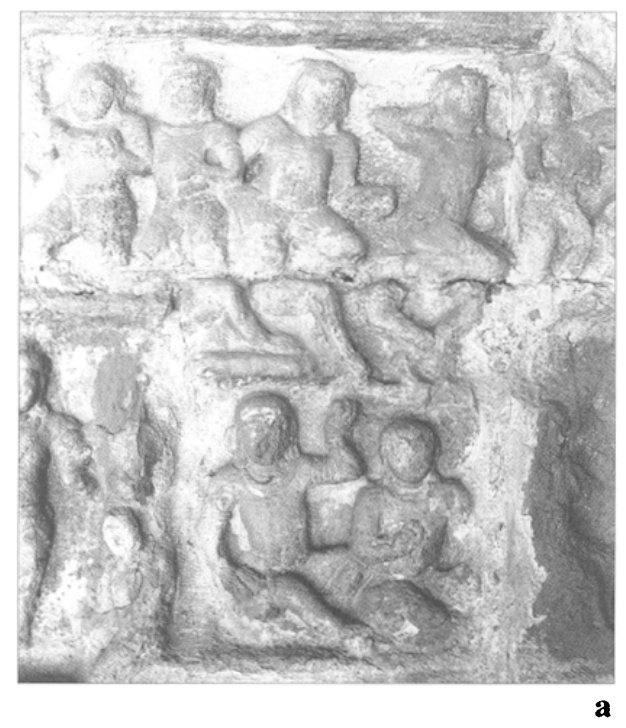

Fig. 8

Relief narratif royal

a. Vaikuṇthaperumāl, Kãñīpuram, ix ${ }^{\mathbf{e}}$ siècle. Cliché : E. Francis.

b. Vaikuṇthaperumā!, Kãñcīpuram, ix ${ }^{\mathfrak{e}}$ siècle. Cliché : E. Francis.

c. Montage à partir de fig. 8a (portion foncée) et fig. $8 \mathrm{~b}$ (portion claire), Vaikuṇțhaperumạ!, Kăñīpuram.

Montage : E. Francis.
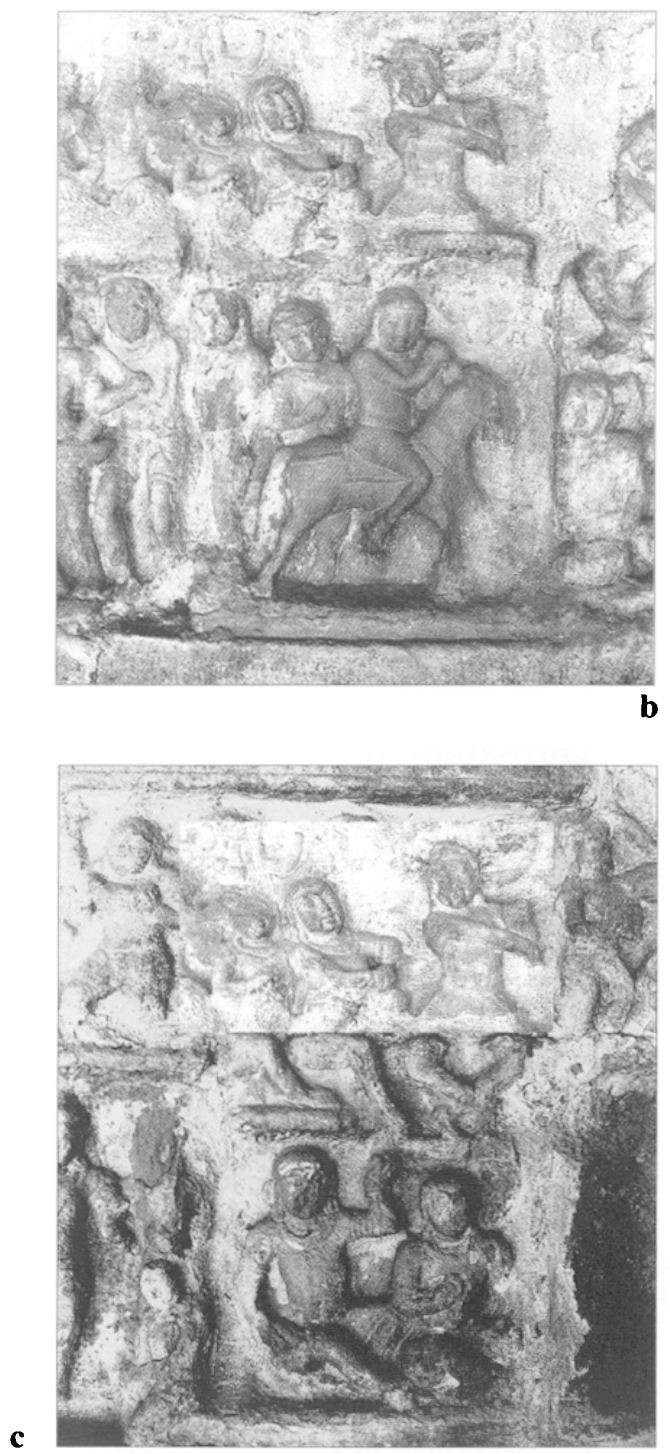

50. Ces incongruités se concentrent sur l'aile sud de la galerie : un fragment y est même replacé sens dessus dessous et ailleurs les deux morceaux de la bande verticale séparant les panneaux d'une même rangée ne correspondent plus. 
Le vimāna lui-même comporte de nombreuses formes uniques et en tant que telles d'identification délicate. L'incertitude des identifications amène à être prudent en ce qui concerne la logique qui sous-tend un programme iconographique dont certains éléments nous échappent encore. On peut cependant d'ores et déjà la dessiner à grands traits, et souligner d'autres aspects, très caractéristiques, du temple. Tout d'abord, on retrouve, comme au Kailāsanātha, une première face de la circumambulation, la face nord dans le cas présent, consacrée aux formes paisibles de la divinité, et plus particulièrement à la transmission de la connaissance. Hayaśiras, forme de Viṣnu associée aux Veda qu'elle remet à Brahmā, apparaît au moins une fois, peut-être deux. Ailleurs, Viṣnu assis sur un serpent semble enseigner à un personnage qui l'écoute attentivement et un autre panneau est parfois interprété comme Nara-Nārāyaṇa. Aucun dieu en action n'apparaît ici, au contraire de la face sud, la troisième de la pradaksinā, consacrée aux avatāra: Vāmana, Narasiṃha, Varāha sont représentés, ainsi qu'une figure féminine dans laquelle on reconnaît Mohinī ${ }^{51}$. On retrouve donc des orientations qui, déterminées par la circumambulation, sont très semblables à celles du shivaïte Kailāsanātha. On est loin pourtant de l'esprit quasi syncrétique animant ce dernier. Au Kailāsanātha, les formes de la Déesse et les avatāra de Viṣnu sont très présents sur l'enceinte des cinquante-huit chapelles. De nombreuses déesses sont aussi représentées sur le sanctuaire même. Mais le programme iconographique du Vaikunțhaperumāl ignore pratiquement les divinités féminines : quelques apsaras décorent la face nord entre les panneaux consacrés à Viṣnu ; Mohinī - encore une forme de Viṣnu - danse au sud. Force est de constater que la Déesse n'a guère de place ici, pas même sous la forme de Lakșmī, son épouse. Quant à l'iconographie shivaïte, l'usage en est très particulier au Vaikunthaperumāl.

Śiva, formant couple avec un Brahmā symétrique, apparaît en adoration de Viṣnu ${ }^{52}$, dans une position de subordination donc. Par ailleurs les formes de Viṣnu plagient manifestement l'iconographie shivaïte. L'article d'Adalbert J. Gail (2003) nous a confortés - si besoin était - dans l'évidence que la face est du temple plaque sur des schémas shivaïtes très reconnaissables des figures de Viṣnu. Commençons par la plus évidente : Viṣnu assis enroule une guirlande autour du chignon d'un dévot agenouillé devant lui. Sans la conque et le disque que porte le dieu dans ses mains supplémentaires, on l'identifierait comme Śiva couronnant son dévot Candeśa. Cette légende est représentée dans la sculpture méridionale dès l'époque pallava avec exactement les mêmes caractéristiques iconographiques que celles du panneau du Vaikuṇthaperumāl . La représentation vishnouite est en revanche un exemple unique. Son identification pose problème. Qui Viṣnu couronne-t-il? A. J. Gail propose de reconnaître Prahlāda dans le dévot agenouillé. Narasimha étant représenté trois fois dans le Vaikunthaperumāl, cette hypothèse est plausible. Tout comme celle de Viṣvaksena, suggérée par G. Vijayavenugopal (EFEO, Pondichéry), qui dans les temples médiévaux vishnouites remplit une fonction parallèle à celle de Candeśa dans les temples shivaïtes. Mais il nous paraît important ici de replacer l'image dans le

51. Les deux panneaux le plus à l'ouest sur cette face sud sont énigmatiques. Ils ne correspondent pas à des images connues d'avatāra.

52. Par exemple, de part et d'autre de la porte qui perce le mur ouest se trouvent des panneaux symétriques avec un grand Viṣnu adoré, d'un côté par Brahmā, de l'autre par Śiva. 
cadre d'une rivalité avec le mouvement shivaïte dont l'iconographie est ici détournée. Le même procédé est en effet utilisé dans l'ensemble de la face est. Il suffit pour s'en convaincre de considérer la représentation du Govardhanadhara. Krṣna, n'étaient certains détails (ses deux bras au lieu de quatre), est très proche de représentations, antérieures, de Śiva Gañgādhara, comme celle du Kailāsanātha (fig. 9-10) ${ }^{53}$. On se souvient de la complémentarité organisée à Mahābalipuram entre les deux grands reliefs de la Descente du Gange et de Krṣna Govardhanadhara. On la retrouve ici, transfigurée en un Krṣṇa qui porte la montagne, cependant que le mouvement de ses jambes, de ses bras, de sa tête et la composition de l'image, jusqu'au dévot occupant à son côté gauche la place de Pārvatī, dessinent en filigrane la silhouette de Gangādhara. À l'angle nord-est, la représentation, très originale, est sans doute inspirée par un appendice méridional du Harivamśa (appendice I.41 ; A. Couture 2007) qui décrit « la manifestation du lotus » plus en détail que dans l'édition critique : une divinité, sortant à mi-corps d'un fût particulier et adorée par Śiva et Brahmā, s'inspire des Lingodbhavamūrti shivaïtes. Sur le quatrième panneau, Śiva et Viṣnu, qui le domine légèrement, se font face ${ }^{54}$. Ce mur nous paraît donc définitivement devoir être compris comme celui d'une rencontre entre les deux divinités, présentant Śiva comme subordonné à Viṣnu, au compte duquel sont reprises nombre des figures shivaïtes les plus courantes de l'art pallava.

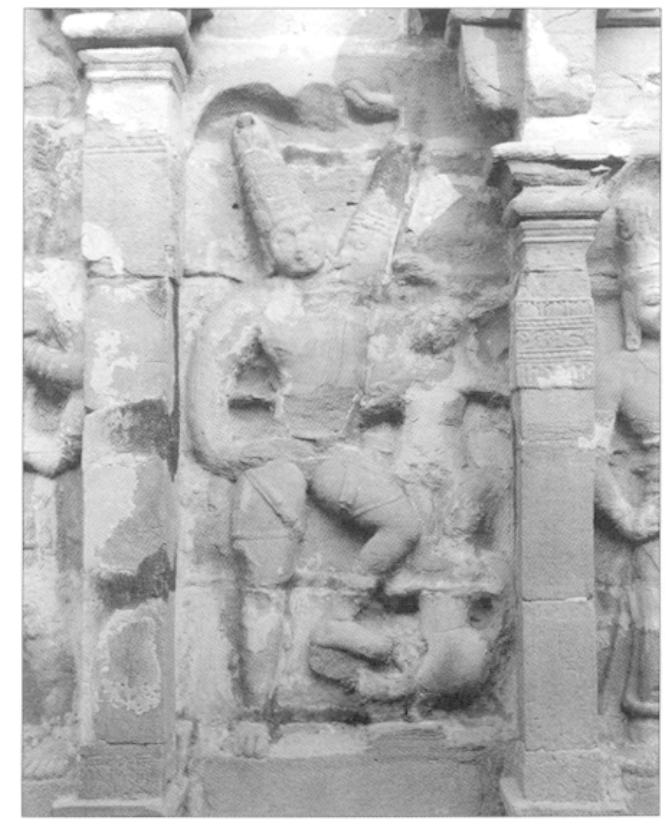

Fig. 9

Krṣna Govardhanadhara, vimāna, face est, Vaikuṇṭhaperumăl, Kāñcīpuram, I $\mathrm{X}^{\mathrm{e}}$ siècle.

Cliché : E. Francis.

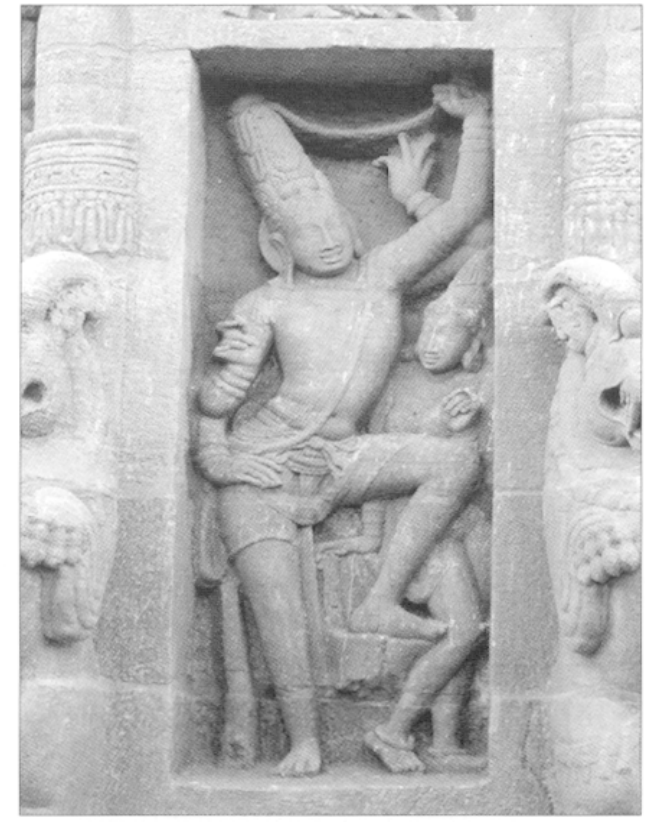

Fig. 10

Gañgădhara, vimāna, face nord, Rãjasiṃheśvara au Kailāsanātha, Kãñcīpuram, viII ${ }^{\mathrm{e}}$ siècle. Cliché : K. Kataoka.

53. Gangādharamūrti, analogue divin privilégié du roi dans la sculpture et l'épigraphie royale pallava, est étudié dans E. Francis (en cours).

54. Nous sommes tentés d'y voir un Harihara à la « sauce » vishnouite du ix siècle. 
Le même procédé d'une inspiration détournée nous paraît expliquer également au moins l'une des représentations du deuxième niveau du temple, auquel on accède par un escalier intérieur. Les deux premiers panneaux rencontrés sont perpendiculaires et semblent former une paire. Sur le premier, sept personnages assis regardent le Viṣnu du deuxième panneau. Ce dernier évoque la Tripurāntakamūrti de Śiva avec qui il partage l'arc. Peut-ĉtrc a-t-on affaire à une forme de Trivikrama, luttant contre les démons avant d'enjamber les mondes? L'inspiration shivaïte est en tout cas certaine ${ }^{55}$ et d'autant plus remarquable que cette représentation de Viṣnu se retrouve dans les petits reliefs des soubassements de temples shivaïtes cōla. Viennent ensuite, toujours dans le sens de la circumambulation: sur la face ouest, Keśivadha; sur la face nord, Gajendramokșa, Rāma (?), le barattage de l'océan, l'histoire de Narasiṃha (deux panneaux « violents », dont l'éviscération) et Krṣnna contre Kāliya ; sur la face est, la geste de Krșna ${ }^{56}$ (se rendant en char à Mathurā ; y combattant les lutteurs engagés par son oncle ; Kamsa célébrant un aśvamedha (?) ; meurtre de Kamsa) ; sur la face sud : trois panneaux où Viṣnu chevauchant Garuḍa est engagé dans des combats, Śeșaśāyana et deux panneaux qui semblent mettre Rāvana en scène ; sur la face ouest : le même Rāvana recevant la grâce de Brahmā ${ }^{-57}$, puis Trivikrama et Vāmana à la perpendiculaire. Un système d'opposition différent opérerait donc au deuxième étage consacré intégralement aux formes combattantes et d'avatāra de Viṣnu.

\section{Navigating Hudson ${ }^{58}$}

The Body of God de D. Dennis Hudson (à paraître) proposera sans nul doute une autre vision que la nôtre. Dans ses articles préliminaires, l'auteur interprète les images de culte et le programme iconographique du Vaikunțhaperumāl d'après la théologie pāñcarātra et le Bhāgavata-purāna ${ }^{59}$. Cette thèse - dont il tire par ailleurs des implications pour l'histoire plus ancienne du vishnouisme qui ne nous

55. Cette correspondance avec l'iconographie shivaïte est renforcée par l'usage que fait cette dernière des Tripurāntakamūrti. Ceux-ci nous paraissent en effet fonctionner comme des versions shivaïtes de l'avātara, et plus particulièrement de Trivikrama. Le symbolisme des trois villes et des trois pas a dû faciliter le rapprochement entre les deux formes. À cet égard, notons que les deux panneaux complémentaires de la version vishnouite du Tripurāntakamūrti au Vaikuṇṭhaperumāḷ représentent Vāmana et Trivikrama.

56. La geste de Krsṣna enfant est reconnaissable, pensons-nous, sur certains des petits panneaux qui ornent le parapet de ce premier étage.

57. Il s'agit ici d'un nouvel exemple de reprise ou de réponse vishnouite au shivaïsme qui représente fréquemment la Rāvanānugrahamūrti. Pour la source textuelle où Brahmā remplace Śiva, voir Rāmāyana III.30.17 et VII.10.10-12.

58. D'après le titre de l'article de Michael W. Meister 2002.

59. Voir D. Hudson 2002a et 2002b. Nous n'avons pas pu consulter ses articles de 1993 et 1995 ce qui rend notre appréciation sujette à révision - où l'auteur a peut-être répondu par avance à nos objections. 
concernent pas directement ici ${ }^{60}$ - souffre, de notre point de vue et pour ce que nous en connaissons, de son caractère monographique. Tout d'abord, D. Hudson spécule sur l'ouverture à l'ouest de ce temple vishnouite sans rendre compte du fait que quatre des sept temples shivaïtes pallava de Kāñcīpuram s'ouvrent également dans cette direction ${ }^{61}$. Le Vaikunțhaperumāl est par ailleurs le plus ancien des temples vishnouites du pays tamoul à comporter trois cellas superposées pourvues d'images de culte. Or tous sont actuellement de rite vaikhānasa (voir G. Colas 1986 : 58) et, parmi eux, le Sundaravaradaperumāl à Uttaramērūr offre un exemple bien documenté de convergence avec les prescriptions de la Maricisamhitā d'obédience vaikhänasa ${ }^{62}$. Nous nous demandons donc si ce type de temples à trois paliers ne serait pas propre à cette école du vishnouisme et s'il existe des textes pāñcarātra qui le décrivent. Enfin, nous pensons que le Vaikuṇthaperumāl ne peut se comprendre sans référence au Kailāsanātha qui le précède de quelques décennies. Il constitue, en quelque sorte, la riposte vishnouite à cette fondation royale shivaiite. Il s'en inspire, sans doute, en ce qui concerne la thématique de ses façades selon l'ordre de la circumambulation, et, indéniablement, pour ce qui est de l'iconographie. Nous ne pouvons alors nous empêcher de comprendre son orientation et sa localisation dans le paysage urbain de Kāñcīpuram comme une opposition délibérée au Kailāsanātha.

Signalons par ailleurs que les trois images du couloir de circumambulation du premier palier, que D. Hudson identifie comme des caturvyūha de Viṣnu, sont difficiles d'interprétation : l'une a été récemment complètement restuquée et les deux autres révèlent, sous un stuc ancien, quelques rares restes de la pierre originale. L'auteur associe par ailleurs Narasimha à la direction du nord (deux panneaux sur la face nord du deuxième palier) et Varāha à la direction du sud (un panneau sur la face sud du premier palier) ${ }^{63}$ alors que Narasiṃha jouxte le Varāha sur cette même face sud

60. Ce qui explique l'intérêt suscité par les travaux de D. Hudson chez d'autres chercheurs. Voir la liste des contributeurs au Journal of Vaishnava Studies 11.1 (Fall 2002), " Hudson volume » et notamment le point de vue de R. H. Davis.

61. H. Bakker semble également ignorer ce fait, qui a des consćquences sur sa théorie concernant la position de Dakṣināmūrti à la droite du linga de la cella. Son hypothèse ne fonctionne pas dans le cas de ces temples qui sont, pour certains tout du moins, antérieurs à l'exemple le plus ancien qu'il prend en compte (le temple de Tiruttani).

62. Sur les textes vaikhānasa et la Marīcisaṃhitā, le Sundaravaradaperumāl à Uttaramērūr, nous renvoyons aux travaux de François Gros et R. Nagaswamy (1970: $70 \mathrm{sq}$.) pour qui le Sundaravaradaperumāl suit avec « justesse de détails » (p. 81) la Marīcisamhitā et qui se demandent si l'architecte du nom de Parameśvara mentionné à Uttaramērur - dans un rare exemple d'inscription non royale, sanskrite et grantha, au IX ${ }^{\mathfrak{c}}$ siècle - ne serait pas également celui du Vaikuṇthaperumä! Gérard Colas (1986 : 59-60) s'interroge pour sa part sur le sens du terme ägama utilisé dans l'inscription et relève que la Marīcisamhitā se contredit notamment à propos des images des trois cellas superposées. Se pose ici le problème de la convergence d'un temple et d'un texte pour leur datation respective.

63. D. Hudson extrapole à partir de ces données du $\mathrm{VIII}^{\mathfrak{c}}$ siècle de notre ère pour interpréter les images polycéphales anciennes de Viṣnu concernant notamment leur orientation. Ces images dites «Vaikuntha » d'après des textes pāñ carātra sont étudiées entre autres par D. M. Srinivasan et T. S. Maxwell. Hudson est-il influencé par la convergence entre cette dénomination, par ailleurs quelque peu arbitraire, et par le nom du Vaikuṇṭhaperumāl, qui n'est cependant pas son 
du premier palier et que ce dernier apparaît peut-être également sur la face nord du premier palier.

Un autre problème concerne la pertinence du Bhägavata-purāna ${ }^{64}$ pour interpréter l'iconographie du Vaikunțhaperumāl. Aucun des épisodes qui apparaissent avec ce texte pour la première fois dans la tradition sanskrite - le combat de Krṣṇa et Baka, Krṣnna jouant de la flûte, le vol des vêtements des gop ${ }^{-65}$ par exemple - n'y sont, à notre connaissance, représentés. De plus le temple peut se comprendre en recourant au Harivamísa et aux Purāna anciens seulement. Le Bhāgavatapurāna n'est pas nécessaire ${ }^{66}$.

D. Hudson fait pourtant des observations importantes. Il identifie dans le complexe ce qu'il nomme une structure en mandala, avec le vimāna consacré au dieu, puis une fosse ${ }^{67}$, et enfin la galerie dédiée à l'histoire de la dynastie. Cependant plutôt que d'opposer comme lui un vimāna ésotérique et un prākāra exotérique, nous insisterions sur la solution de continuité entre ces deux ensembles : les rois du prākāra sont les pendants des formes combattantes et d'avatāra que le dieu prend sur le vimāna, en particulier au deuxième palier et sur la face sud du premier. En accord avec une partie de l'analyse que D. Hudson propose de l'hymne

nom originel ni n'implique exclusivement un contexte pāñcarātra? Son interprétation du Vaikuṇthaperumā! lui sert d'argument pour appuyer sa théorie de l'existence aux environs du début de notre ère d'une religion vishnouite bhägavata pāñcaratra pleinement constituée. À ce sujet notons que ses interprétations des inscriptions anciennes (Agathoclès, Héliodore) nous paraissent très libres.

64. Le Bhāgavatapurāna nous semble une synthèse, sans doute plus tardive qu'on l'imagine, entre tradition du nord (Harivamśa) et tradition du sud (Nälāyirativviyapirapantam). Se pose aussi, comme dans le cas du Sundaravaradaperumā l et de la Marícisamhitā, le problème du rapport entre texte et archéologie. Qui est premier? Le prestige de la philologie implique peut-être un peu vite la préséance du texte.

65. Il reste à compléter l'étude de la tradition méridionale krșnaïte entreprise par Friedhelm Hardy (1983). Concernant les images et les représentations de Krṣna en pays tamoul, nous avons fait les constatations suivantes. Il y a dès le $x^{\mathfrak{e}}$ siècle au plus tôt des représentations de Kṛ̣na luttant contre Baka dans les séries narratives des soubassements de temples. Nous tenons cet épisode de la geste krșnaiite, ainsi que ceux du vol des vêtements ou du joueur de flûte, comme spécifiquement méridionaux. Ils sont bien connus du Nālāyirativviyapirapantam mais absents du Harivamsía (voir Ch. Schmid 2002). Par ailleurs, à Tiruvellarai, on trouve des représentations de Krṣna dansant avec les pots (épisode que nous ne connaissons que dans le Nāläyirativviyapirapantam) ou fendant la gueule de Baka (dans le Nälāyirativviyapirapantam et le Bhāgavatapurāna) sur des petits panneaux du Puṇạarīākṣaperumāl . Sur le même site, un des linteaux du surprenant puits en forme de svastika porte deux panneaux latéraux avec un lion qui encadrent trois panneaux centraux, où de gauche à droite, Krṣna lutte successivement contre Keśin, Arișta et Baka. Ces images sont de datation difficile - le Puṇạaīkākșaperumā! est peu étudié et le puits a fait l'objet d'une rénovation dès l'époque médiévale - mais dateraient au plus tôt du I $X^{\mathfrak{e}}$ siècle.

66. Voir John Stratton Hawley (2002: 6) qui fait la même remarque à propos de temples cālukya du VIII" siècle.

67. D. Hudson suggère qu'elle était périodiquement inondée. Il faudrait vérifier si l'archéologie du site confirme cette possibilité. Si tel était le cas, pourrait-on voir dans le Vaikunțhaperumāl un exemple des temples miroirs qu'a étudiés B. Dagens (2000:184-186)? 
de Tirumankai (Periya Tirumoli II.9) ${ }^{68}$ - quand il relève une structure unique dans le corpus du Nālāyirativviyapirapantam, chaque première moitié de strophe étant consacrée au dieu et l'autre au roi patron - il est clair que le temple entretient un rapport particulier avec la royauté ${ }^{69}$. Cependant comme l'a fait remarquer Richard H. Davis à un autre propos ${ }^{70}$, D. Hudson se focalise sur le point de vue théologique de l'ācārya. Partant de textes et de conceptions théologiques, il souligne certes l'importance du temple pour son roi patron, mais n'en tire pas, nous semble-t-il, toutes les conséquences. D. Hudson ne rend pas réellement compte de l'autonomie et du discours d'autres agents impliqués dans la conception de ce temple : les architectes, les artisans, et surtout le roi patron.

Il semble donc que le désaccord entre les vues de D. Hudson et les nôtres soit grand. Nous avons soulevé quelques questions qui nous empêchent d'accepter son hypothèse en l'état. Mais, par ailleurs, nos recherches n'expliquent pas le temple d'un point de vue théologique. Nous nous focalisons sur les images - observées en tant qu'objets d'abord autonomes et relevant d'un autre langage - et sur le point de vue royal du patron, en recourant à d'autres corpus que $\mathrm{D}$. Hudson (les inscriptions et les

68. Nous ne suivons pas D. Hudson quand il établit une correspondance signifiante entre certaines formes des strophes et celle des cellas (debout, assis, couché). Pour prendre l'exemple de la première strophe :

colluvan col porul tān avai āy cuvai üru oli nārram torramum āy

nal aran nārañān nānmukañukku ịtam tān tatam cūlntu alaku àya kacci

pallavan villavan en ru ulakil palar àyp pā vēntar vanariku kalal

pallavan mallaiyar kōn paninta paramēccuravinnakaram atuvē

"Il est le verbe et le sens du verbe, la saveur, le contact, le son, l'odeur et l'apparence ;

Pour lui qui est le bon Hara, Nārāyaṇa et Brahmā, il est un lieu : Kacci la belle, ceinturée d'étangs ;

Le Pallava archer, dont les bracelets de pieds sont adorés par les autres rois, nombreux dans le monde à l'appeler ainsi,

Le roi Pallava de Mallai y est humble, au Parameśvaravișnugrha que voilà ». (Traduction : E. Francis d'après l'édition de Es. Jekatrațcakan, Chennai, 2002.)

Pour D. Hudson, cette strophe évoque une forme assise qui correspond à celle du premier palier, ce qui nous paraît forcé. On ne peut traduire comme lui dans cette première strophe : " And Narayana now controls Śiva, the auspicious destroyer and Brahma the four-faced creator » (D. Hudson 2002b : 17). Utilisons-nous des éditions si différentes de l'hymne? Et quand bien même on accepterait que cette strophe se réfère à un Viṣnu assis, comment être sûr que le poète pense à une image précise du temple, ou que c'est celle que nous pouvons voir aujourd'hui? Il nous semble typique des hymnes de la bhakti tamoule corpus et du processus d'universalisation des dieux que, chantant le dieu d'un temple, le poète dévot évoque toutes les formes du dieu. Il n'y a pas, à notre avis, concordance directe entre formes évoquées dans un hymne et images sculptées du temple auquel l'hymne se rapporte. Le pandit Varada Desikan (EFEO, Pondichéry) nous a fait part d'un sentiment identique.

69. On peut se demander par ailleurs comment comprendre cette insistance particulière du poète sur le dieu et sur le roi. Nous y voyons plutôt qu'un mouvement du roi vers la bhakti, ses poètes et ses sanctuaires, un mouvement en sens inverse : du poète vers le roi, le premier peut-être à patronner un temple vishnouite de pareille envergure.

70. R. H. Davis (2002: 38-41) considère avec méfiance l'extrapolation dans le passé qu'opère D. Hudson à partir de son interprétation du Vaikunthaperumāl, se demandant s'il ne projette pas dans le passé le point de vue de ses sources qui justement cherchent à inscrire leur tradition dans une antiquité lointaine, source d'autorité et de légitimité. 
monuments royaux). Le temple du Vaikunthaperumāl, œuvre de plusieurs agents, est polysémique et ce caractère justifie des approches différentes. Nous attendons donc avec impatience la parution de The Body of God.

\section{Conclusions}

Au terme de cette chronique, nous voudrions formuler quelques remarques concernant la rivalité sectaire, la répartition des espaces divin et humain dans l'iconographie des temples et l'emplacement des images.

Un jeu sectaire, voire une rivalité plus militante, nous paraît manifestement opérer sous les Pallava. En témoignent les réaménagements effectués au Temple du Rivage ou dans la grotte de Mahișāsuramardinī à Mahābalipuram. Le Vaikuṇțhaperumāl, par ailleurs, fournit un exemple de shivaïsation de l'inspiration iconographique dans un temple vishnouite. En tant que tel, nous le considérerons comme un témoignage particulièrement original des rivalités au sens large pouvant opposer les deux mouvements de bhakti à certains moments de leur histoire.

La répartition des images divines et humaines dans l'espace du temple s'effectue selon des modalités différentes d'un édifice à l'autre. Au Temple du Rivage, le grand sanctuaire de Śiva est ceint d'un mur recouvert de panneaux très usés où l'on semble reconnaitre des personnages à quatre bras et la plus grande enceinte porte en certains endroits des reliefs narratifs royaux. Au Kailāsanātha, un tel espace n'est pas donné aux représentations directes du roi : dans l'enceinte des cinquante-huit chapelles, les Śiva, les avatāra de Viṣnu et les formes armées de la déesse - ces deux derniers à comprendre comme des extensions de Śiva - ont pris place. Au Vaikuṇthaperumāl, on en revient à une galerie royale, mais sur tout le pourtour du temple cette fois, où les rois Pallava, peut-être formes incarnées de Viṣnu, encadrent de leurs exploits le sanctuaire d'un dieu qui figure sur le premier panneau de la galerie royale.

Quant aux images, nous identifions deux manières de les disposer ${ }^{71}$. La première manière se réfère à l'orientation spatiale. Ainsi Dakṣināāmūrti et les formes apaisées de la Déesse font toujours face au sud tandis que les formes armées ou combattantes de celle-ci regardent au nord. Il y a par ailleurs une complémentarité évidente entre ces deux types de déesses, à l'entrée est de la grande enceinte du Kailāsanātha ou sur les faces nord et sud des mandapa de certains temples construits. Puis Ganapati vient à l'occasion prendre la place de la déesse apaisée sur ces mandapa. La seconde manière se réfère au sens de la circumambulation, et il faut ici se souvenir que les temples pallava construits s'ouvrent tantôt à l'est, tantôt à l'ouest. Nous constatons que la face qui est première dans la circumambulation est celle des formes apaisées et enseignantes (Kailāsanātha, face sud et Vaikuṇṭhaperumāḷ, face nord), tandis que

71. Cette remarque concerne les temples construits uniquement. Le cas de l'art pariétal est quelque peu différent et compliqué par le fait que l'orientation des grottes n'est pas fixe. 
la troisième et dernière est celle de formes combattantes ou d'avatāra (Kailāsanātha, face nord et Vaikuṇthaperumāl, face sud). La face arrière du temple est intermédiaire en des termes, propres à chaque temple, qu'il nous faudra préciser : le Kailāsanātha met en exergue la danse, comme figure de transition ou d'union entre Śiva ascète et Śiva conquérant, tandis que le Vaikunthhaperumāl vante la supériorité de Viṣnu sur les autres dieux, en particulier sur Śiva. La comparaison entre les choix iconographiques opérés dans ces deux temples par rapport aux directions cardinales tendrait à indiquer que le shivaïte Kailāsanātha privilégie l'orientation et le vishnouite Vaikuṇthaperumā! la circumambulation. Quant au Temple du Rivage, particulier du fait qu'il y a deux sanctuaires de Śiva, le petit s'ouvrant à l'ouest et le grand à l'est, il fait clairement primer l'orientation sur l'ordre de la circumambulation : Tripurāntakamūrti se dresse au nord sur les deux temples, tandis que, sur la face sud du petit temple, on devine Dakṣināmūrti, et que sur celle du grand temple, on n'identifie plus qu'un Cakradānamūrti à une extrémité.

Ces quelques pages montrent assez, nous semble-t-il, l'intérêt et l'importance des études pallava pour l'Inde du Sud. On regrettera peut-être que les recherches aient porté si intensivement sur les Cōla, sans avoir entrepris d'examiner en profondeur l'impact des Pallava. Ils furent des innovateurs dans l'iconographie brahmanique, mais aussi dans l'épigraphie sanskrite, puis, dans une certaine mesure, tamoule. Évoquant l'état inachevé de la plupart des monuments de Mahābalipuram, Samuel $\mathrm{K}$. Parker nous engage à les considérer comme des « empowered remnants of lived activities... less like inert art objects and more like sacred ash (vipüti)... seeds, harvested remnants of the previous season of growth, potentials for the next $"{ }^{72}$. Les travaux de Victor Goloubew, Jacques Dumarçay et Françoise L'Hernault sont de ces graines à moissonner afin de rendre compte de l'héritage des Pallava. C'est ce but que nous poursuivons.

72. L'auteur touche là peut-être un point essentiel de la mentalité hindoue, mais on n'est pas sûr de sa pertinence pour comprendre le site de Mahābalipuram où des raisons plus pratiques ont pu jouer qui expliquent l'état inachevé de la plupart des monuments. On a évoqué entre autres la mort du patron, l'épuisement de ses ressources financières ou encore son accaparement par la nécessité de guerroyer. 


\section{BIBLIOGRAPHIE}

ARE : Annual Report on Epigraphy, New Delhi, Archaeological Survey of India.

BAKKER, Hans

2001 «Dakṣiṇamūrti » dans Karttunen, K. \& Koskikallio, P. (eds.), Vidyārnavavandanam. Essays in Honour of Asko Parpola, Studia Orientalia $\mathrm{n}^{\circ}$ 94, Helsinki : Finnish Oriental Society, p. 41-53.

2004 "At the right side of the Teacher: Imagination, Imagery, and Image in Vedic and Śaiva Initiation » dans GranofF, P. \& Sinohara, K. (eds.), Images in Asian Religions: Texts and Contexts, Vancouver-Toronto, University of British Columbia Press, p. 117-148.

BissChOP, Peter

2006 Early Śaivism and the Skandapurāna. Sects and Centres, coll. « Groningen Oriental Studies " ${ }^{\circ} 21$, Groningen, Egbert Forsten.

BRoCQuet, Sylvain

1997 Les inscriptions sanskrites des Pallava: poésie, rituel, idéologie, Villeneuve d'Ascq, Septentrion.

Colas, Gérard

1986 Le temple selon Marīci. Extraits de la Marīci-samhità étudiés, édités et traduits, coll. "Publications de l'Institut Français d'Indologie " $\mathrm{n}^{\circ} 71$, Pondichéry, Institut Français d'Indologie.

Coomaraswamy, Ananda K.

1935 Elements of Buddhist Iconography, Cambridge (Massachussets), Harvard University Press.

Couture, André

2007 La vision de Mārkandeya et la manifestation du Lotus, histoires anciennes tirées $d u$ Harivamśa (ed. cr., Appendice I, $n^{\circ} 41$ ), coll. « Hautes Études Orientales », $n^{\circ} 43$, École pratique des hautes études, Sciences historiques et philologiques, Genève, Droz.

Dagens, Bruno

1976 Mayamata. Traité sanskrit d'architecture. Édition critique, traduction et notes. $2^{e}$ partie, coll. "Publications de l'Institut Français d'Indologie » $\mathrm{n}^{\circ} 40$, Pondichéry, Institut Français d'Indologie.

2000 « Le temple et le miroir à travers le monde indien » dans BARAZERBilloret, M.-L. \& Fezas, J. (éd.), La Norme et son application dans le monde indien, Paris, EFEO, p. 175-191.

Davis, Richard H.

1997 Lives of Indian Images, Princeton, Princeton University Press.

2002 «Hudson revisits Bhāgavata Thoughts », Journal of Vaishnava Studies 11.1 (Fall 2002), p. 27-43.

DUMARÇAY, Jacques

1975 Temples Pallava construits. Étude architecturale, coll. « Mémoires Archéologiques $» n^{\circ} 9$, Paris, EFEO.

EcK, Diana L.

1982 "Gangā: the Goddess in Hindu sacred Geography » dans HawleY, J.S. \& Wulff, D.M. (eds.), The Divine Consort. Rādhā and the Goddesses of 
India, coll. « Berkeley Religious Studies Series », Boston, Beacon Press, p. 166-183.

EI : Epigraphia Indica, New Delhi, Archaeological Survey of India.

FrancIS, Emmanuel

[en cours] Le discours royal. Inscriptions et monuments pallava, thèse de doctorat, en préparation à l'Institut orientaliste de l'Université Catholique de Louvain.

GAlL, Adalbert J.

2003 «Prahlādānugrahamūrti am Vaikuntha Perumāl-Tempel », Berliner Indologische Studien, 15-17, p. 413-420.

GiLlet, Valérie

2006 La création d'une iconographie śivaïte narrative. Incarnations du dieu dans les temples pallava construits, thèse de doctorat, Paris, Université Paris III.

Goloubew, Victor

1914 «La falaise d'Arjuna de Mavalipuram et la descente de la Gangâ sur la terre, selon le Râmâyana et le Mahâbhârata », Journal Asiatique, $11^{\mathrm{e}}$ série, Tome 14, p. 210-212.

1921 «La descente de la Gañgā sur la terre à Mavalipuram » dans Goloubew, V. (éd.), Sculptures Çivaïtes. Études et documents publiés sous la direction de V. Goloubew, coll. «Ars Asiatica », n 3, Paris \& Bruxelles, Librairie nationale d'art et d'histoire \& Van Oest et Cie, p. 23-25.

GoOdall, Dominic

2004 Parākhyatantram. The Parākhyatantra. A Scripture of the Saiva Siddhānta. $A$ critical edition and annotated translation by Dominic Goodall, « Collection Indologie $» \mathrm{n}^{\circ}$ 98, Pondichéry, IFP / EFEO.

Goodall, Dominic, Rout, Nibedita, Sathyanarayanan, R., Sakda, S.A.S., Ganesan, T., Sambandhasivacarya, $\mathrm{S}$.

[2005] The Pañcāvaranastava of Aghoraśivācārya, A twelfth-century South Indian prescription for the visualisation of Sadâsiva and his retinue, "Collection Indologie $» \mathrm{n}^{\circ} 102$, Pondichéry, IFP / EFEO.

Gros, F \& Nagaswamy, R.

1970 Uttaramērūr. Légendes, histoires, monuments (avec le Pañcavaradaksetra māhātmya édité par K. Srinivasacharya), coll. « Publications de l'Institut Français d'Indologie » $\mathrm{n}^{\circ} 39$, Pondichéry, Institut Français d'Indologie.

HARDY, Friedhelm

1983 Viraha-Bhakti. The early History of Krșna Devotion in South India, New Delhi, Oxford University Press.

HAWLEY, John Stratton

2002 «Introduction », Journal of Vaishnava Studies, 11.1 (Fall 2002), p. 1-14.

Hudson, D. Dennis

1993b «Vāsudeva Krșna in Theology and Architecture: a Background to Śrīvaiṣnavism », Journal of Vaishnava Studies 2.1 (Winter 1993), p. 13970. [article non consulté] 
1995 «The Śrimad Bhāgavata Purāna in Stone: the Text as an eighth Century Temple and its Implications ", Journal of Vaishnava Studies 3.3 (Summer 1995), p. 137-182. [article non consulté]

2002a "Early Evidence of the Pāñcarātra Āgama » dans HARPER, K. A. \& Brown, R. L. (eds.), The Roots of Tantra, coll. "SUNY Series in Tantric Studies", Albany, State Lniversity of New York Press, p. 133-167.

2002 b "The Discovery ", Journal of Vaishnava Studies 11.1 (Fall 2002), p. 15-26.

[à paraître] The Body of the God: an Emperor's Palace for Krishna in $8^{\text {th }}$ Century Kaimal, Padma Kanchipuram, New York, Oxford University Press.

1999 «Shiva Nataraja. Shifting Meanings of an Icon », Art Bulletin 81.3, p. 390419.

2005 «Learning to see the goddess once again: Male and Female in Balance at the Kailāsanāth Temple in Kāñcīpuram », Journal of the American Academy of Religion, 73.1 (March 2005), p. 45-87.

L'HERnault, Françoise

1975 Temples Pallava construits. Étude iconographique, coll. « Mémoires Archéologiques $» n^{\circ} 9$, Paris, EFEO.

1978 L'iconographie de Subrahmanya au Tamil Nadu, coll. «Publications de l'Institut Français d'Indologie » $n^{\circ}$ 59, Pondichéry, Institut Français d'Indologie.

Lockwood, Michael

1974 Mahābalipuram Studies [avec Siromoney, Gift \& Dayanandan, P.], Madras, Christian Literature Society.

1982 Màmallapuram and the Pallavas, Madras, Christian Literature Society.

1993 Mãmallapuram. A Guide to the Monuments, Madras, Madras Christian College, Tambaram Research Associates.

2001 Pallava Art [avec Vishnu bhat, A. \& Siromoney, G. \& Dayanandan, P.], Madras, Madras Christian College, Tambaram Research Associates.

LONGHuRst, A. H.

1924-30 Pallava Architecture, 3 volumes, coll. « Memoirs of the Archaelogical Survey of India $» n^{\circ} 17,33$ et 40, Simla (vol. 1) \& Calcutta (vol. 2 et 3), Government of India Press.

Mahalingam, T. V.

1988 The inscriptions of the Pallavas, New Delhi, Indian Council of Historical Research \& Agam Prakashan.

MARR, John Ralston

1991 "Note on the Excavations at the Shore Temple, Mahabalipuram », BSOAS 54, p. 574.

Meister, Michael W.

2002 «The Discovery », Journal of Vaishnava Studies 11.1 (Fall 2002), p. 45-9.

MinaKSHI, C.

1941 The historical Sculptures of the Vaikunthaperumāl Temple at Kāñchī, coll. « Memoirs of the Archaeological Survey of India » $n^{\circ} 63$, Delhi, Government of India Press. 
NAGASWAMY, R.

1969 The Kailasanatha Temple (a Guide), coll. « Tamil Nadu State Department of Archaeology Publications » $n^{\circ} 4$, Madras, Government of Tamil Nadu.

1975 «What Mahendra meant?», The Indian Express, Madras edition, Saturday 28.06.1975.

1978 « Mahendra's Inscription at Tiruchirapalli », Studies in ancient Tamil Law and Society, coll. "Tamil Nadu State Department of Archaeology Publications " $\mathrm{n}^{\circ} 47$, Madras, Government of Tamil Nadu.

1979 Tiruttani and Velanjeri Copper Plates, coll. « Tamil Nadu State Department of Archaeology Publications » ${ }^{\circ} 55$, Madras, Government of Tamil Nadu.

1988 «Innovative Emperor and his personal Chapel. Eigth Century. Kanchipuram » dans Dehejia, V. (ed.), Royal Patrons and Great Temple Art, Bombay, Mārg Publications, p. 37-60.

Narasimhan, K. T.

1999 «Recent Discoveries made by Chennai Circle during this Decade » dans Damodaran Nambiar, K. (ed.), Tamil Nadu. Archeological Perspective, coll. «Tamil Nadu State Department of Archaeology Publications » $n^{\circ} 143$, Chennai, Government of Tamil Nadu, p. 156-162.

PARKER, Samuel K.

2001 "Unfinished work at Mamallapuram or, What is an Indian Art Object? », Artibus Asiae, 61.1, p. 53-75.

Parabrahma Sastry, P. V.

1992 « Babbēpalli Plates of Pallava Kumāra Vishṇu », Epigraphia Indica 42 (1977-1978), New Delhi, Archaeological Survey of India, p. 44-56.

Parlier-Renault, Edith

2000 «La légende de Kāma dans les inscriptions et l'iconographie Pallava », Indologica Taurinensia, 26, p. 121-41.

RABE, Michael D.

1996 «The Māmallapuram Praśasti: a Panegyric in Figures », Artibus Asiae, 57.3-4, p. 189-241.

2001 The Great Penance at Māmallapuram. Deciphering a visual Text, Chemmancherry (Chennai), Institute of Asian Studies.

Raman, K. V. \& Sekaran, B. Sasi

1992 "Some rare Sculptures from the Pallava Temples at Kanchipuram » dans Lockwood, M. (ed.), Indological Essays. Commemorative Volume II for Gift Siromoney, Madras, Madras Christian College, Department of Statistics, p. 86-93.

RAMESAN, N.

1976 « Kumaradimangalam Plates of the Pallava King Nandivarma III » dans Subrahmanyam, R. (ed.), Sri Mallampalli Somasekhara Sarma Commemoration Volume, Journal of the Andhra Historical Society, Hyderabad, Government of Andhra Pradesh, p. 193-205. 
RAMESH, K. V.

1993 "A Pallava Charter and two Medallions from Peddamudiyam » dans Murthy, A. V. N. \& Sarma I. K. (ed.), Śr̄ Rāmachandrikā (Professor Oruganti Rāmachandraiya Festschrift). Essays on Indian Archaeology, History, Epigraphy, Numismatics, Art and Religion, Delhi, Book India Publishing Company, p. 117-21.

REA, Alexander

1909 Pallava Architecture, coll. «Archaeological Survey of India, New Imperial Series " ${ }^{\circ} 34$, Madras, Government Press.

Schmid, Charlotte

2002 «Aventures divines de Krṣna : la lïlā et les traditions narratives des temples cōla », Arts Asiatiques, 57, p. 33-47.

2004 « $\bar{A}$ propos des premières images de la Tueuse de buffle : déesses et krishnaïsme ancien », BEFEO, 90-91, p. 7-67.

2006 "Mahābalipuram : la Prospérité au double visage », Journal Asiatique, p. 459-528.

Sivaramamurti, C.

1976 Gañga $\bar{a}$, New Delhi, Orient Longman.

SII : South Indian Inscriptions, New Delhi, Archaeological Survey of India.

SMITH, Walter

1996 «The Viṣnu Image in the Shore Temple at Māmallapuram », Artibus Asiae, 56.1-2, p. 19-24.

1998 «A Note on the original Vaișnava Character of the Shore Temple, Māmallapuram », Artibus Asiae, 58, p. 30-31.

SRINIVASAN, P. R.

1958-60 «Two Noteworthy Sculptures in the Madras Museum », Journal of Indian Museums, 14-16, p. 11-13.

WILLIS, Michael

2004 "The Archaeology and Politics of Time» dans Bakker, Hans T. (ed.), The Vākattaka Heritage. Indian Culture at the Crossroads, coll. "Gonda Indological Studies »n ${ }^{\circ}$ 13, Groningen, Egbert Forsten, p. 33-58. 